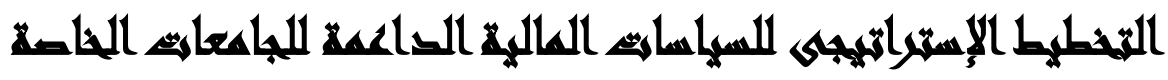

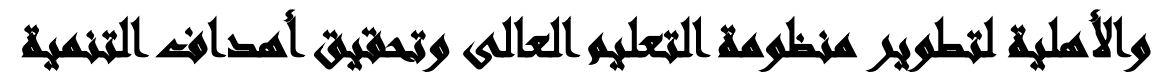

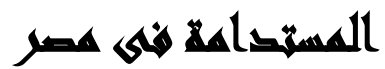

[IV]

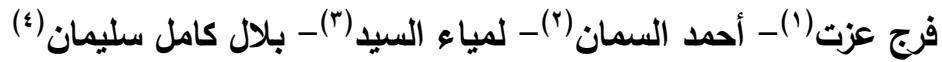

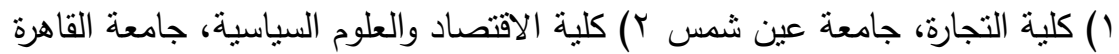

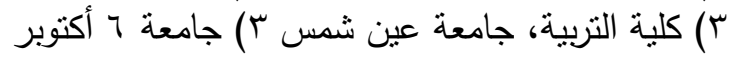

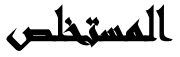

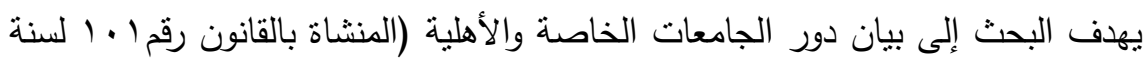

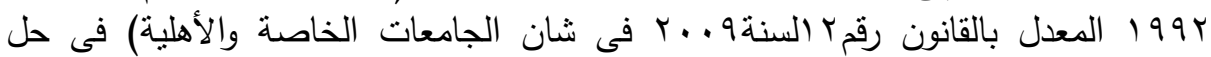

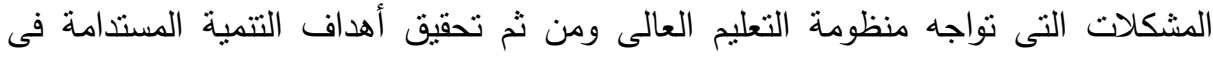

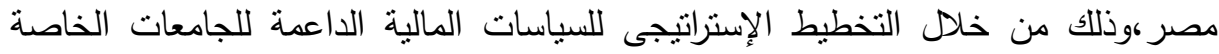

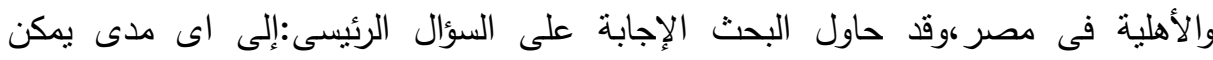

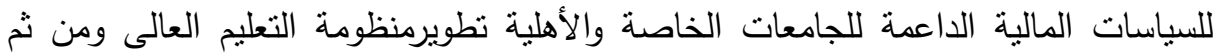

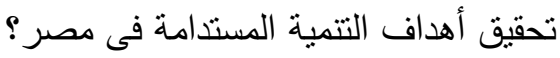

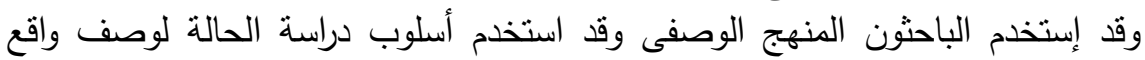

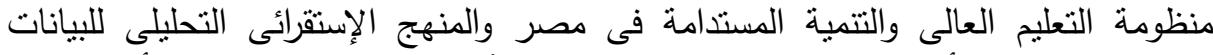

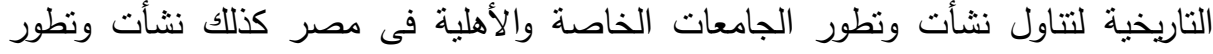

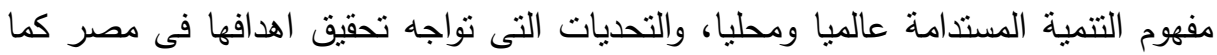

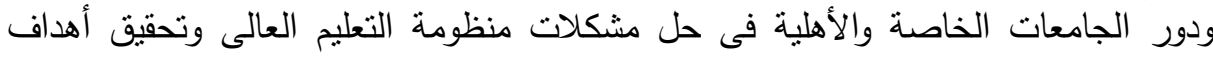

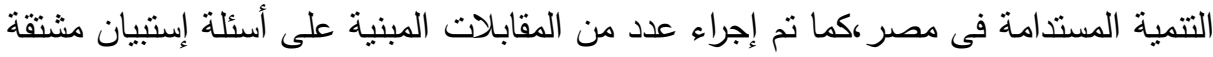

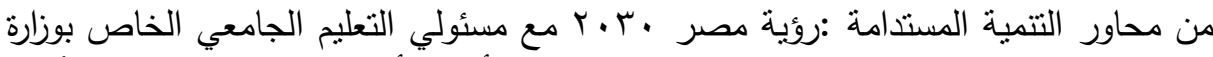

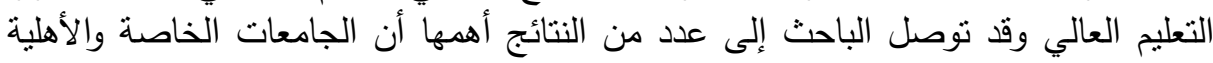

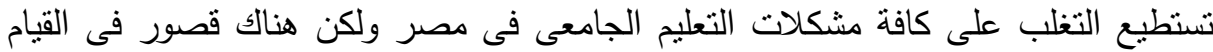

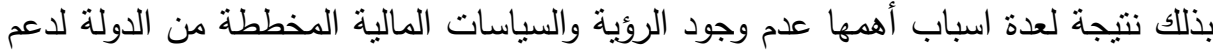

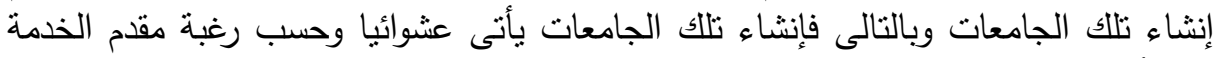

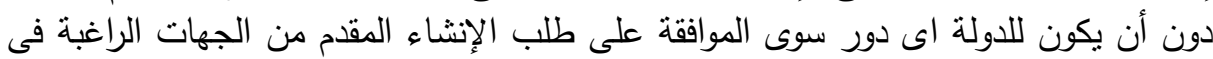

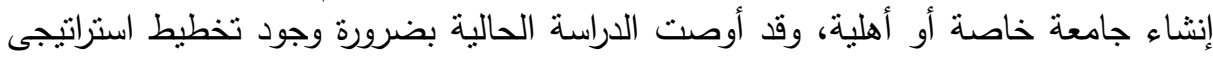

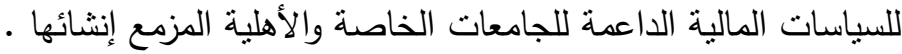

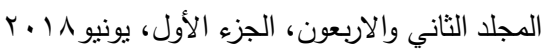




\section{xasadl}

يعد التعليم وخاصة التعليم العالي، من أهم دعامات تحقيق التتمية الاقتصادية للدول

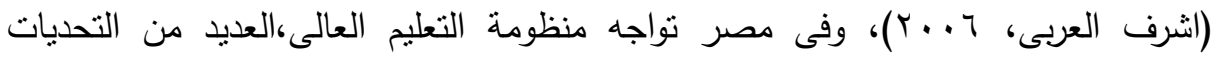

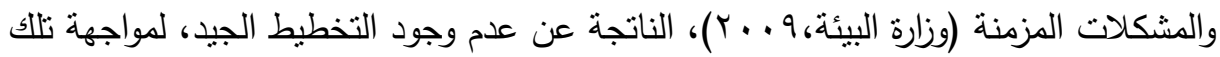
التحديات والمشكلات التى نواجه منظومة التعليم العالى مثل زيادة اعداد الطلاب الملتحقين

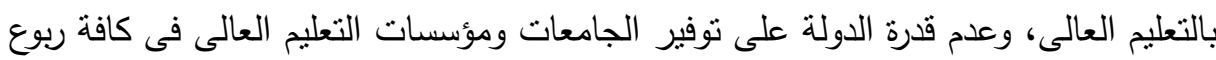

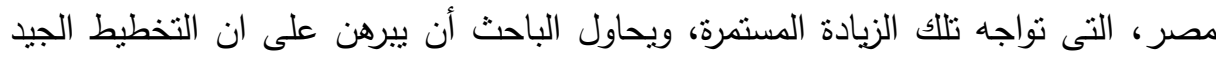
هو التخطيط الإستراتيجي الذى ياخذ فى الإعتبار التحديات التى نواجه تحقيق اهداف التتمية

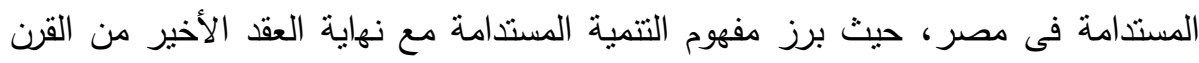

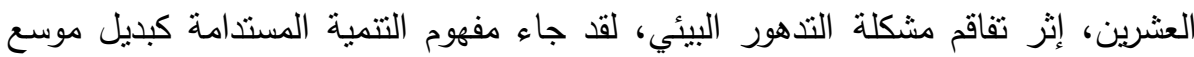
لمفاهيم تتموية سابقة،هذا المفهوم يقضى بان إثباع حاجات الحاضروالارتقاء بالرفاهية الاجتماعية، لا يجب أن يكون على حساب قدرة الأجيال القادمة في تلبية احتباجاتها المادية

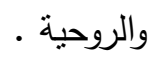

\section{and}

تمثلت إثكالية الدراسة الحالية فى إيجاد حلول للمشكلات التى تواجه منظومة التعليم

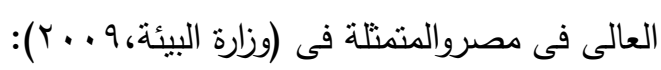

1- ازدياد الضغط على الإلتحاق بالتعليم العالى بسبب زيادة السكان.

r- القصور في نوعية التعليمز

r- القصور في الالتحاق بالتعليم العالي في بعض المناطق منل جنوب سيناء والصعيد والوادي

$$
\text { الجديد ومطروح. }
$$

ع - الضعف الثديد في الصلة بين البحث العلمي وبرامج التتمية والتطوير • ه- ضعف ميزانية الدولة المخصصة للبحث العلمي ( أقل من ا و \%سنويا). 


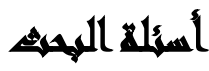

وحاول هذا البحث الإجابة على السؤال الرئيسى:إلى اى مدى يمكن للسياسات المالية

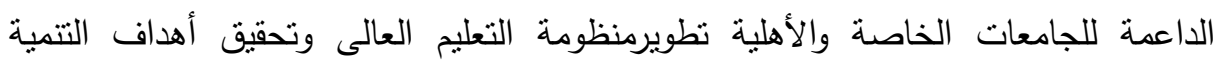
المستدامة فى مصر ؟ والذى يتفرع منه التساؤلات الفرعية التالية:

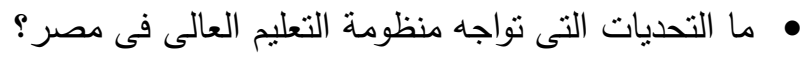

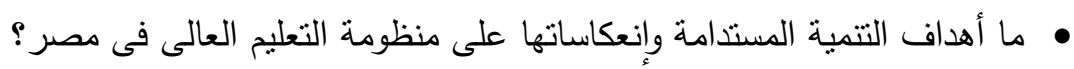

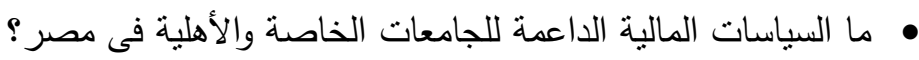

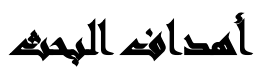

تهدف الاراسة الحالية إلى تحليل ودراسة النقاط التالية:

1- دور الجامعات الخاصة والأهلية فى حل مشكلات منظومة التعليم العالى فى مصر .

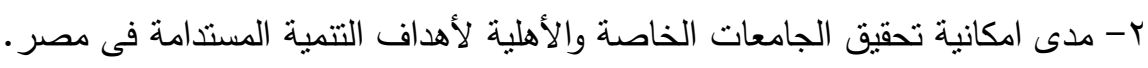
r- دور السياسة المالية للاولة فى تشجيع التوسع فى إنشاء الجامعات الخاصة والأهلية فى ع - دور السياسة المالية للدولة فى توجيه الجامعات الخاصة والأهلية لخدمة المجتمع والبيئة

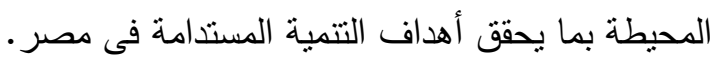

\section{أهمية المهمه}

تتمنل أهمية الدراسة الحالية فى بيان مدى إمكانية إستخدام السياسات المالية للدولة لدعم مؤسسات التعليم الجامعى الخاص والأهلى كأحد المحاور التى نساهم فى علاج السيه السلبيات

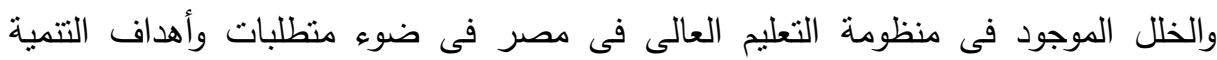
المستدامة كما تكمن أهمية البحث في إمكانية استفادة عدة أطراف منه منل وزارة التعليم العالي، الجامعات الخاصة والأهلية، مؤسسات الأعمال، الطلبة الملتحقين بالتعليم العالى. 


\section{مسوت الهمهث}

الحدود الموضوعية: تتمثل فى الجامعات الخاصة والأهلية فى جمهورية مصر العربية

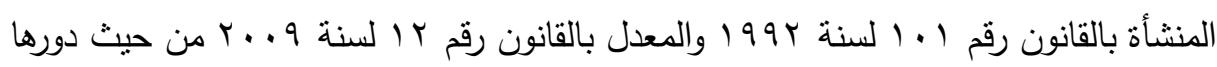
فى حل المشكلات التى نواجه منظومة التعليم العالى فى مصر فيخرج عن نطاق الدراسة

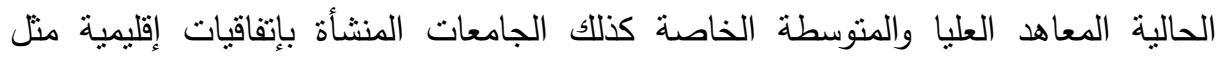
الأكاديمية العربية للعلوم والتكنولوجيا والنقل البحرى ودولية منل الجامعة الأمريكية. الحدود المكانية: تتمثل فى دراسة واقع منظومة التعليم العالى فى مصر . الحدود الزمانية: نعالج الدراسة الحالية واقع منظومة التعليم العالى فى مصر فى الفترة من

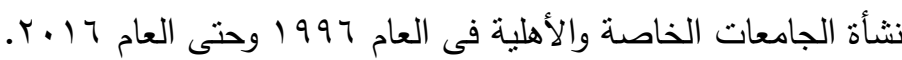

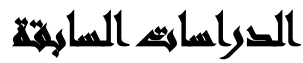

ا - دراسة د.أشرف العربى واخرون 9 9 . ب بعنوان " تمويل التعليم العالى فى مصر

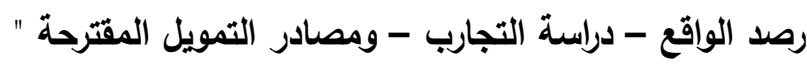

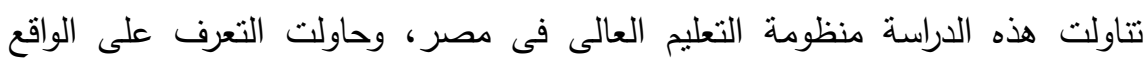

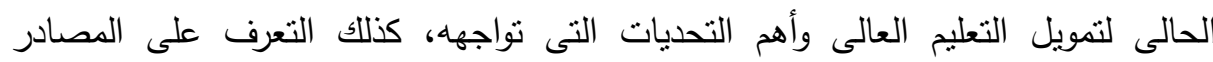
المقترحة لتمويل التكلفة الإضافية لتحقيق هدف الجودة والإتاحة فى التعليم العالى، فى ضواءهو عدد من التجارب الدولية بالإضافة إلى تقدير حجم التمويل الإضافى الممكن تدبيره للتعليم

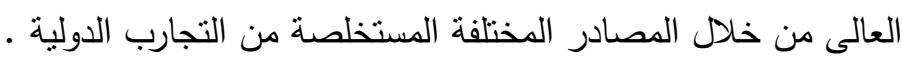

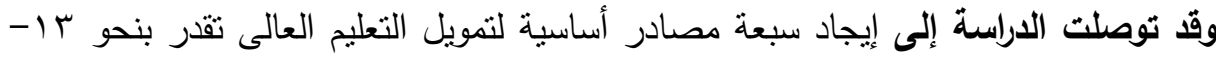

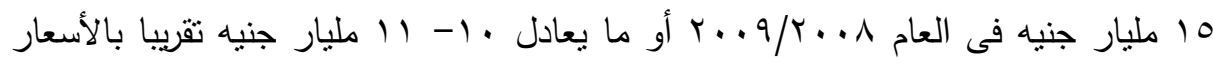

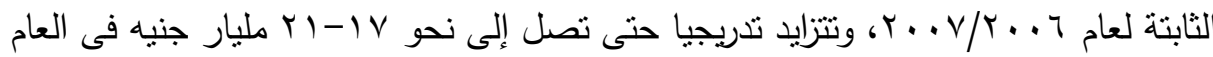

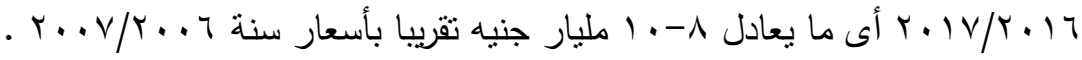


تتفق مع الدراسة الحالية فى تتاولها لمنظومة التعليم العالى ومحاولة إيجاد الحلول

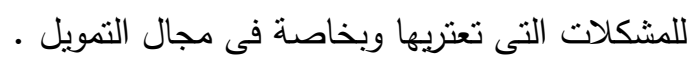

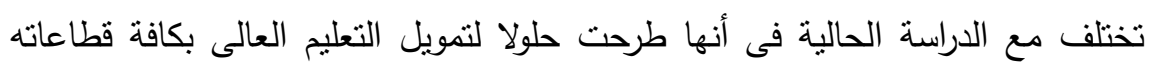

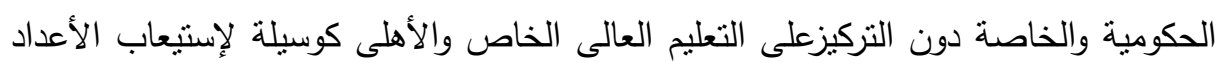

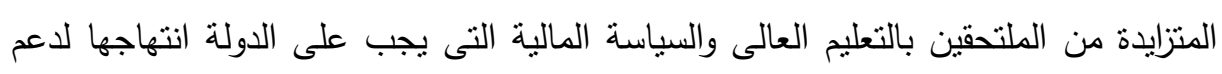

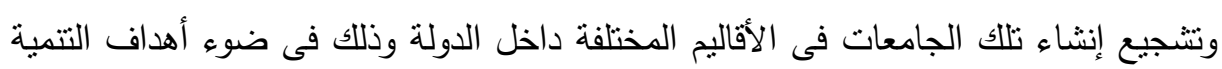
المستدامة . r - دراسة د ـ سمير رياض هلال واخرون 9 . . ب بعنوان "دراسة ميدانية لتكلقة التعليم العالي في مصر".

تهاف هذه الدراسة إلى بحث مشكلة تمويل التعليم العالى الذى يقف عائقا أمام توفير فرص

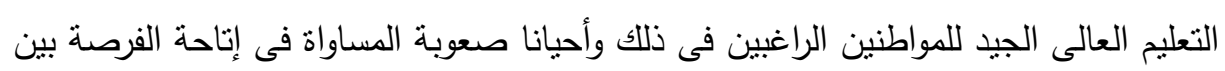

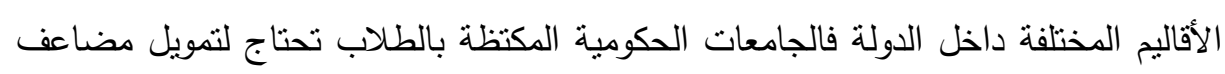

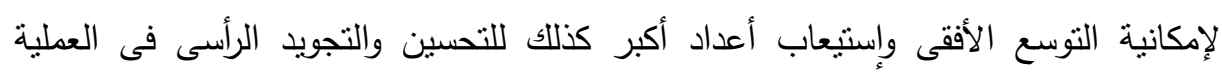
التعليمية كما أن المؤسسات التعليمية الخاصة غير متاحة لكثير من المواطنين لعدم قدرتهم

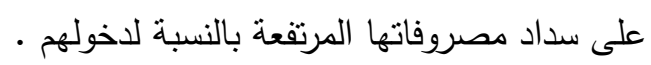

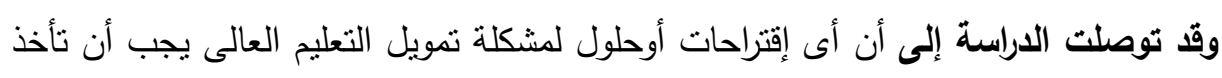
فى الإعتبار العوامل الأتية: • كفاية التمويل من المصادر المتاحة ليس فقط لإستمرار مؤسسات التعليم العالى وإنما لضمان الأداء الأكاديمى والبحثى بمستوى جودة يتيح لها المنافسة إقليميا ودوليا. • الإستقلال المالى للجامعات ونظام الموازنات وأساليب رفع كفاءة الإنفاق.

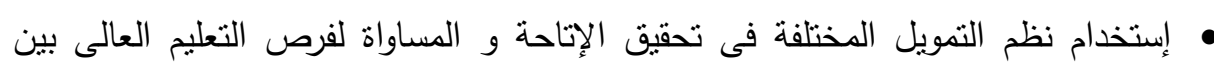
أبناء الوطن. تتقق مع الدراسة الحالية فى تتاولها لمشكلة تمويل التعليم العالى وتأثيرها على عنصرى

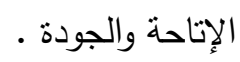


تختلف معها فى تتاولها لمبادئ عامة لوضع الحلول لمشكلة التمويل وعدم تركيزها على معلى

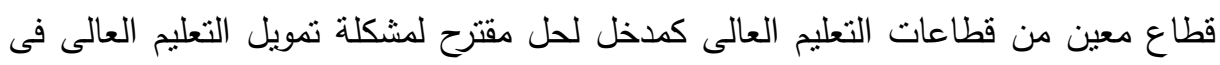
r ب دراسة غادة محمد رأفت صادق 9 . . r " خريطة التعليم الجامعى فى مصر " باستخدام نظم المعلومات الجغرافية دراسة فى جغرافية الخدمات تهاف هذه الدراسة الى الوقوف على مواقع الجامعات الخاصة وانتشارها فى ربوع مصر ومدى تأثيرها فى التخفيف من حدة التكدس فى الجامعات الحكومية. وقا توصلت الباحثة إلى انه يجب تشجيع مشاركة القطاع الخاص فى مجال خدمات التعليم الجامعي مسايرة للنظام العالمي الجديد الذي يشجع اقتصاديات السوق.

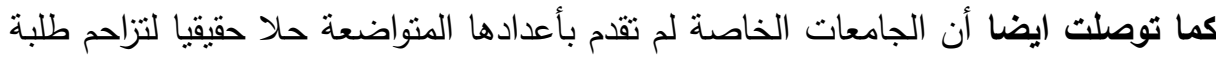

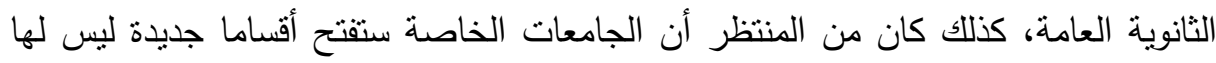
نظير فى الجامعات الحكومية، وستواكب آخر المستجدات فى ميدان التعليم الجامعي. وقد لوحظ تركيز تلك الجامعات الجديدة على أقسام لا تتطلب تكلفة رأسمالية كبيرة كفروع الهندسة

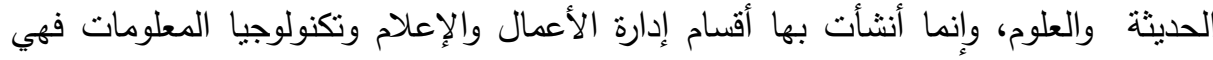
بذلك تكرر ما هو موجود بالجامعات الحكومية، وبالتالى يمكن القول بأن دور الجامعات

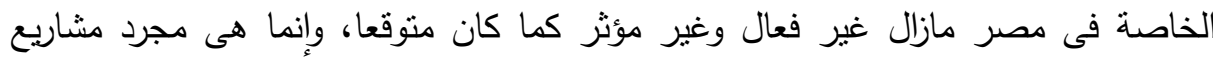
استثمارية الغرض الأساسى منها الربح المادي.

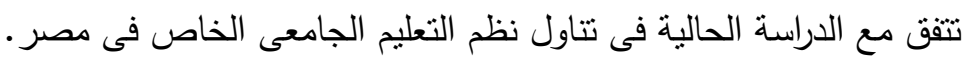
تختلف معها فى عدم تتاولها للتخطيط الإستراتيجي للسياسة المالية الداعمة للجامعات

ع - دراسة شريف أحمد حلمي حسين اللمعي V . . Y:" التخطيط لتطوير التعليم الجامعي الخاص في ضوء احتياجات التنمية ".

تهذف هذه الدراسة الى الوقوف على مداخل التخطيط لنطوير التعليم العالي الجامعي الخاص فى ضوء احتياجات التتمية، وذلك من خلال استعراض مداخل التخطيط لتطوير التعليم العالي 
الجامعي الخاص، كذلك استعراض الأهداف والتوجيهات الاستراتيجية في الخطط القومية

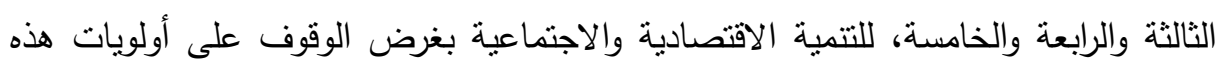
الخطط والعمل على تلبيتها من خلال نطوير نظام التعليم الجامعي الخاص في مصر ، وأخيرا

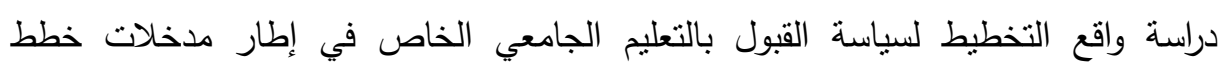
التتمية، وذلك للوقوف على اتجاه السياسة التعليمية في مصر من حيث التوسع في التعليم الجامعي الخاص في مقابل موقفها من التوسع في التعليم الجامعي الحكومي.

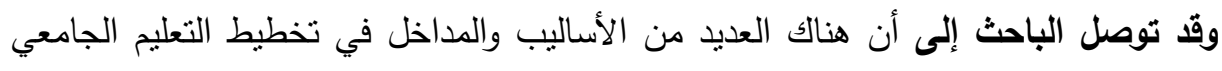

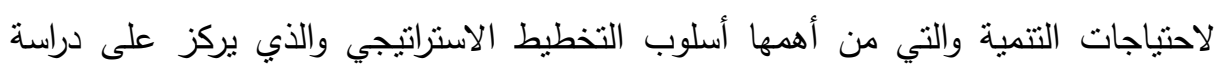

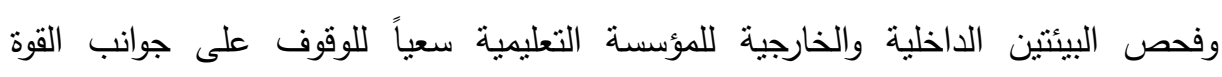

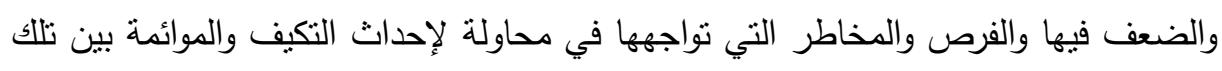

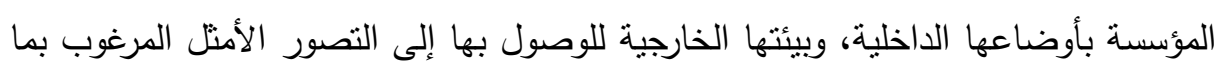

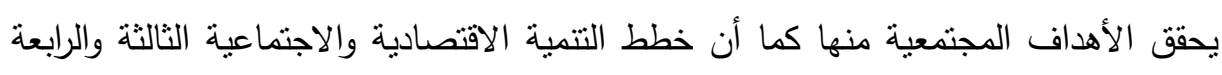
والخامسة تركز على إعطاء القطاع الخاص الدور الأكبر في عملية التتمية، وتقديم كافة التهات

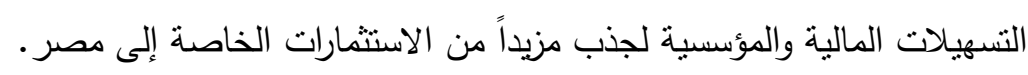
تتفق مع الدراسة الحالية فى تتاول التعليم الجامعى الخاص فى مصر .

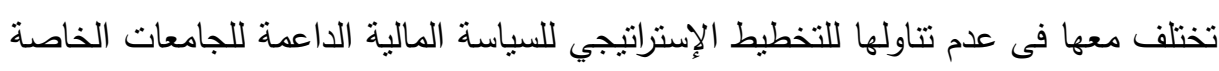

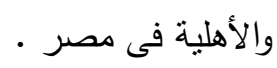

ه - دراسة لمياء محمد أحمد r . . . ب بعنوان " تخطيط سياسات التعليم العالي في مصر في ضوء متغيرات الإقتصاد الحر".

تهدف هذه الدراسة إلى بحث التطورات التى طرأت على سياسات تخطيط التعليم نتيجة المتغيرات المجتمعية والعالمية . وقد توصلت الباحثة إلى انه يجب العادة النظر فى تخطبط سياسات التعليم العالى بحيث تحقق التتسيق بين مؤسسات التعليم العالى بمواردها البشرية والبحثية وبين مؤسسات واعلئ وانظمة

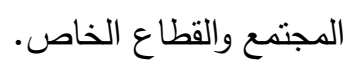

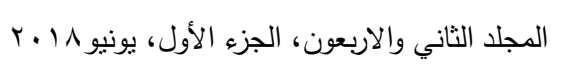


تتفق مع الدراسة الحالية فى تتاول النطورات الإقتصادية وتأثيرها على منظومة التعليم العالى فى مصر.

تختلف معها فى عدم تتاولها للمشكلات التى تعترى منظومة التعليم العالى فى مصر ومحاولة إقتراح تصور لحل تلك المشكلات فى ضوء السياسة المالية للدولة واهداف التتمية

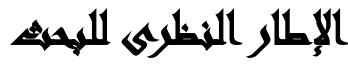

وقد تتاول الباحث منظومة التعليم العالى فى مصر وما بها من مشكلات، والتتمية

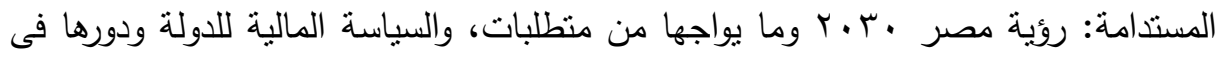

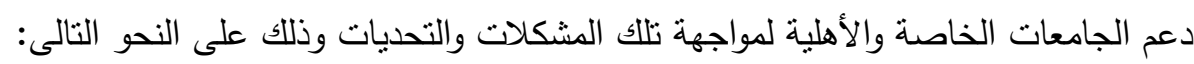
ا - المشكلات التى تواجه منظومة التعليم العالى فى مصر: أدركت وزارة التعليم العالى فى مصر التحديات والمشكلات التى تواجه منظومة التعليم العالى فبادرت بتأسيس لجنة قومية لإصلاح التعليم العالى فى العام 1997 وذللك لتسليط الضوء على التحديات التى تواجه التعليم العالى فى مصر ووضع إستراتيجية تعليمية للتعامل معها مما ادى إلى

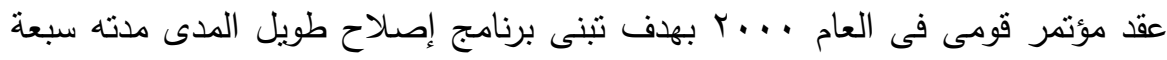

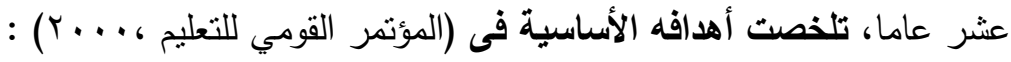
ا -رفع الكفاءة بمنح الجامعات مزيدا من الإستقلال وترشيد الإعنمادات المالية الحكومية. r-رفع الجودة بتدريب أعضاء هيئة التدريس والإداريين والعمل بنظام التمويل التتافسى. r-تحسين جودة ونوعية التعليم الفنى وإصلاح مناهجه، ودعم إدارته، وتعزيز مؤسساته الصغيرة كما أكد المؤتمر على ان تمويل التعليم العالى مسؤولية تضامنية لاتقع على عاتق الحكومة وحدها

وقد بدأت وزارة التعليم العالى والدولة للبحث العلمى بداية من العام ؟ ... فـى تتفيذ

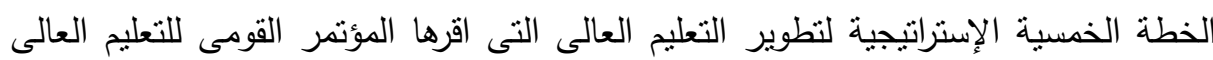


والتى انتهت فى العام V. . r، وتمثلت المرحلة الأولى من تلاك الخطة فى" رفع القدرات

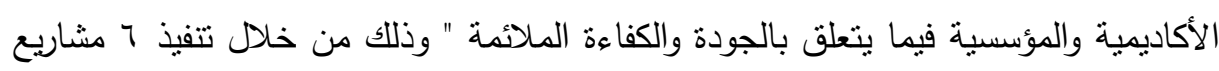

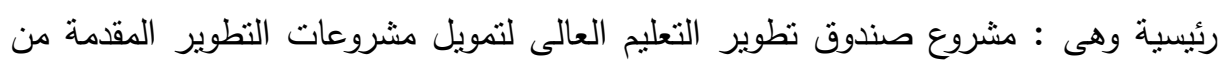

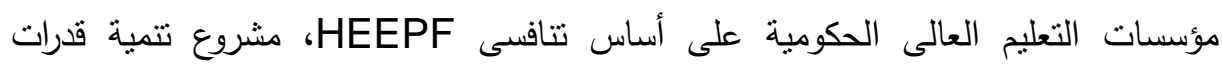

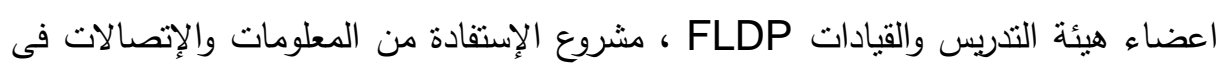
منظومة التعليم العالى ICTP، مشروع تطوير كليات التربية FOEP، مشروع تطوير التعليم

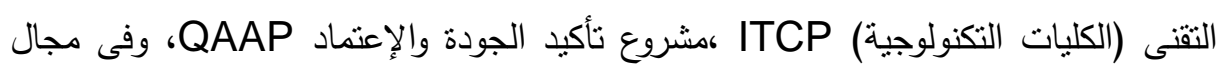
التطوير التشريعى والهيكلي والبنية الأساسية للتعليم العالى " طرحت وزارة التعليم العالى والدولة

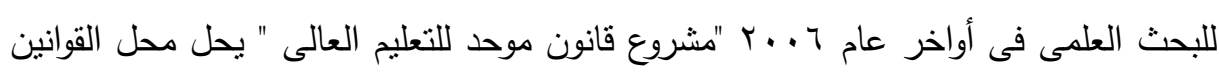
والتشريعات والقرارات الحالية التى تتظم العمل فى مؤسسات التعليم العالى على إختلافها

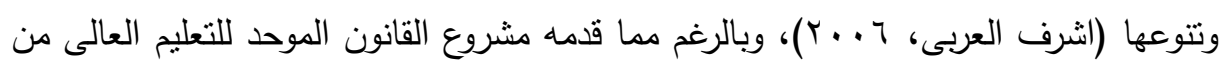

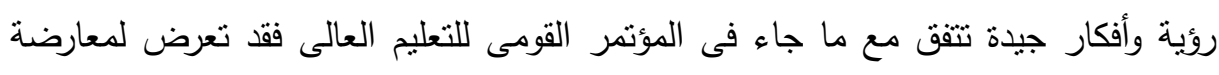

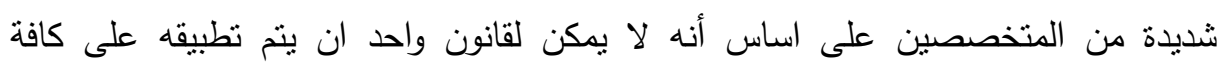

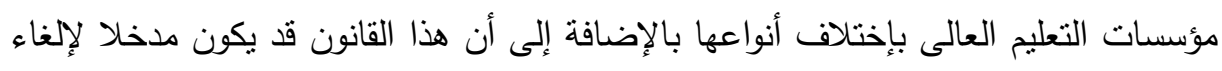

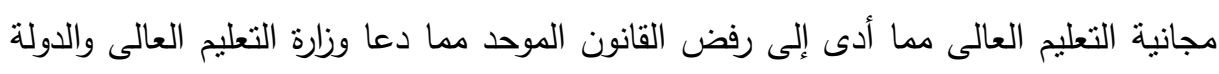

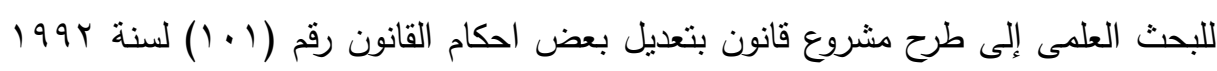

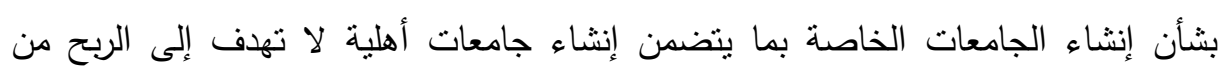

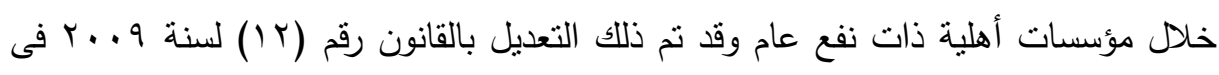
شأن إضافة الجامعات الأهلية.

وقد حدد التقرير الصادر من وزارة البيئة بعنوان " نحو استراتيجية وطنية للتتمية المستدامة " التحديات والمشكلات فى مجال التعليم والبحث العلمي والمتمثلة فى (وزارة البيئة، 1 - ازدياد الضغط على الإلتحاق بالتعليم العالى بسبب زيادة السكان. r- القصور في نوعية التعليم. 
r- القصور في الالتحاق بالتعليم العالي في بعض المناطق منل جنوب سيناء والصعيد والوادي الجديد ومطروح.

$$
\text { ـ- ـ- الضعف الثديد في الصلة بين البحث العلمي وبرامج التتمية والتطوير . }
$$

r - نشأة وتطور الجامعات الخاصة والأهلية فى مصر: يطلق لفظ جامعة خاصة على كل مؤسسة تعليمية غير حكومية تدخل فى نطاق التعليم العالى، يلتحق بها الطلبة

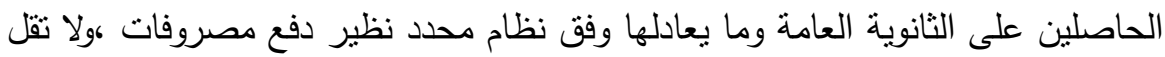
مدة الدراسة بها عن أربع سنوات دراسية ،وتتمتع بالاستقلالية فى تصريف شئونها المالية

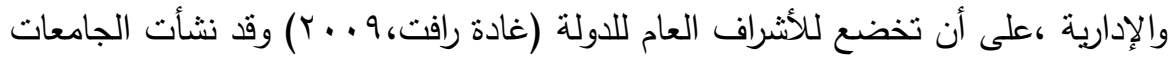
الخاصة بموجب القانون رقم 1. 1 لسنة ب9991، وهى تختلف عن انماط التعليم الجامعى الخاص السابق لها ،منل الجامعة الأمريكية بالقاهرة ،والأكاديمية العربية للعلوم والتكنولوجيا والنقل البحري، من حيث النشأه، وقد حدد في القانون اهداف وكيفية انشاء الجامعة

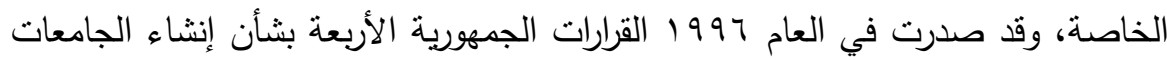

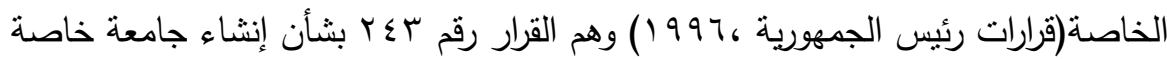

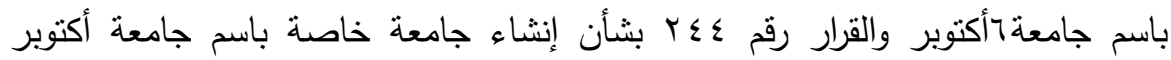

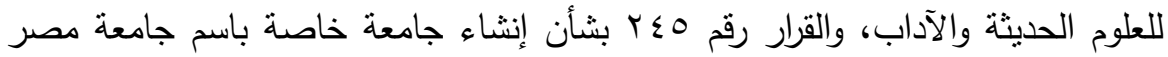

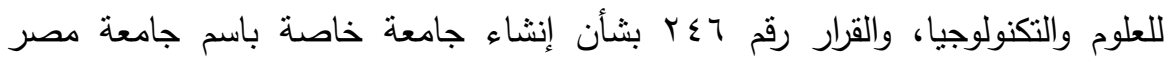

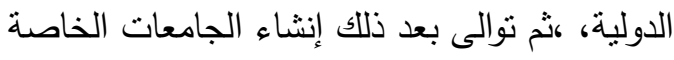




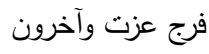

جدول رقم(1): الجامعات الخاصة والأهلية فى مصر من 997 1-7 1.r

\begin{tabular}{|c|c|c|c|c|}
\hline مقرها & أقَرل الإنشاء & الرينشاء & 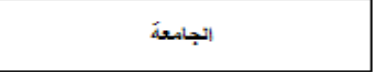 & م \\
\hline \multirow{3}{*}{ 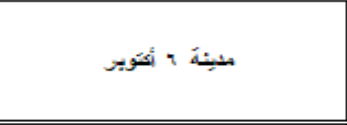 } & 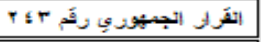 & \multirow{4}{*}{1949} & 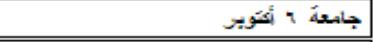 & 1 \\
\hline & 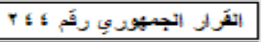 & & 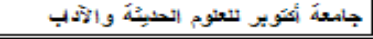 & $i$ \\
\hline & 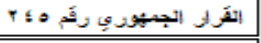 & & جامعة مصر لتعثوم و التعثو نوجيا & $r$ \\
\hline 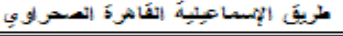 & 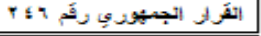 & & جامعة مصر الثولية & 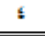 \\
\hline منبذة التشروقة & 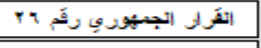 & \multirow{2}{*}{$r+r$} & |اتجامعة اتفرنسبة & 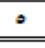 \\
\hline 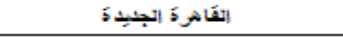 & 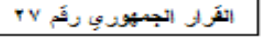 & & إنجامعة الألمدية & 9 \\
\hline 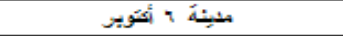 & 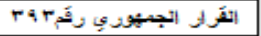 & \multirow{3}{*}{$r \cdots s$} & 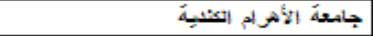 & $\mathrm{v}$ \\
\hline منبية اتشروق & 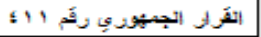 & & إنجامعة أبريطلدِية & A \\
\hline 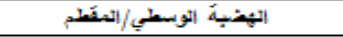 & 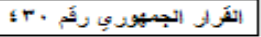 & & 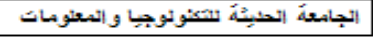 & 9 \\
\hline 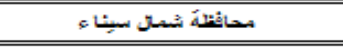 & 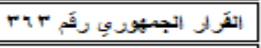 & r... & جامعةُ سبنَاء & 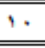 \\
\hline 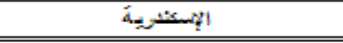 & 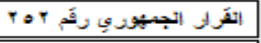 & \multirow{5}{*}{$r \cdots$} & جامعة ثُروس & $\cdots$ \\
\hline تحافيلةً بنب سوبف & 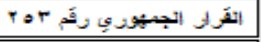 & & جاسعةَ اتهنهية & $i r$ \\
\hline 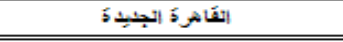 & 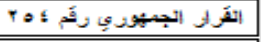 & & جامعةَ إتسنَبَّل & ir \\
\hline 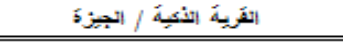 & 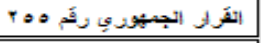 & & 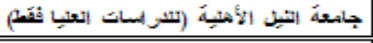 & $1:$ \\
\hline منبية بذر & 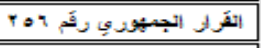 & & |انجامعةُ انعصريةً اتووسبيةً & 10 \\
\hline 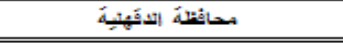 & 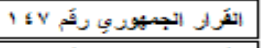 & $r \cdots v$ & 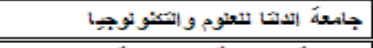 & 19 \\
\hline عِن شتس & 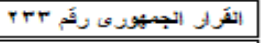 & $r \cdots A$ & 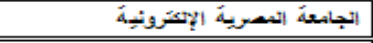 & $1 \mathrm{v}$ \\
\hline الأمسثريةً & 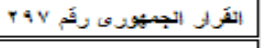 & \multirow{3}{*}{$r \cdots$} & جامعة انسلحل الثشساتي (حت الإنشاء) & $\mathrm{A}$ \\
\hline ألقاهركً - بنيس & 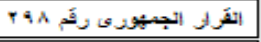 & & إمعلة نتيويونيس & 19 \\
\hline مبيثة انعاتُر هن رمضان & 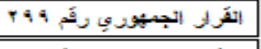 & & جامعةُ انعاُشر هن رمضان & $r \cdot$ \\
\hline اتهنيا اتجندئ & 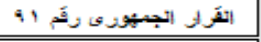 & \multirow{3}{*}{$r \cdot \cdot$} & جامعة لرية & +1 \\
\hline هربسى شطروع & 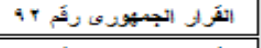 & & 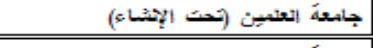 & 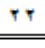 \\
\hline مبنية ب انكوّير & 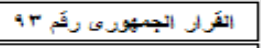 & & 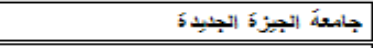 & $r t$ \\
\hline منبية بذر & 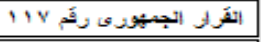 & \multirow{4}{*}{$r+i t$} & جامعةَ بذر & Ts \\
\hline |إنقاهركً & 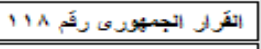 & & 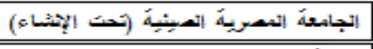 & ro \\
\hline 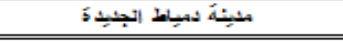 & 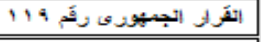 & & جامعةَ حورس & 79 \\
\hline 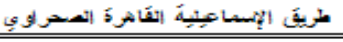 & 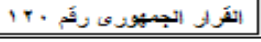 & & إنجامعة اتحضريةً (تحت الإنشاء) & $\mathrm{rv}$ \\
\hline
\end{tabular}

المصدر: إعداد الباحث من خلال المواقع الإلكترونية للجامعات الخاصة

r- أهداف التنمية المستدامة روئية مصر • ب • ץ: قامت وزارة التخطبط والمتابعة

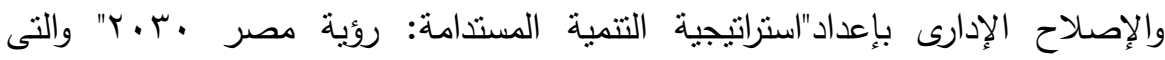

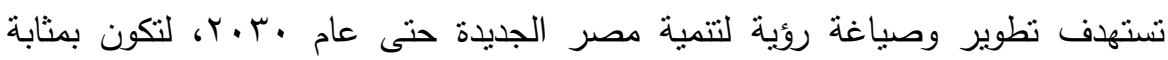

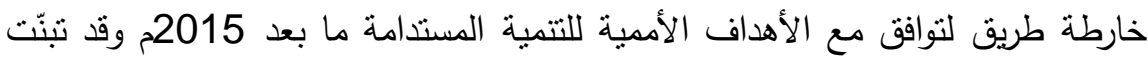
الاسراتيجية مفهوم التتمية المستدامة كإطار عام يُقصد به تحسن جودة الحياة في الوقت لهن 
الحاضر بما لا يخل بحقوق الأجيال القادمة في حياة أفضل تتضمن "إستراتيجية التتمية

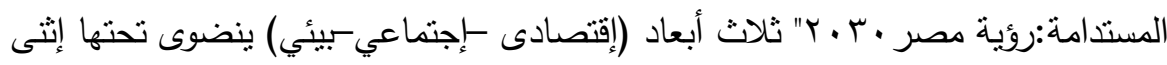
عشر محوراً وهى:

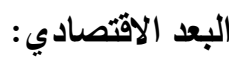
المحور الأول التتمبة الاقتصادبة: بحلول عام 2030 يكون الاقتصاد المصري اقتصاد سوق

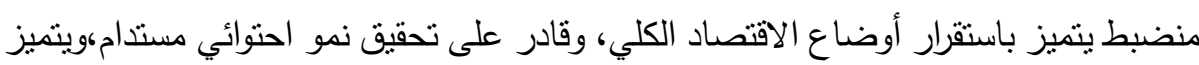

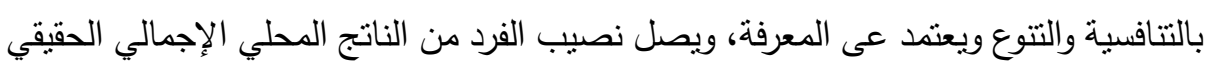
إلى مصاف الدول ذات الدخل المتوسط المرتفع. بعض الأهداف الرئيسية:

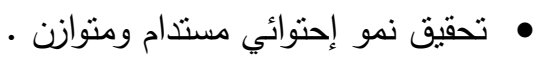

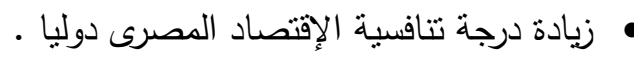

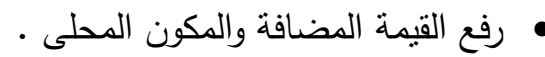

المحور الثاني الطاقة: بحلول عام 2030 يصبح قطاع الطاقة قادراً عى تلبية كافة منطلبات التتمية الوطنية المستدامة من موارد الطاقة وتعظيم الاستفادة الكفؤة من مصادرها المتتوعة (تقليدية ومتجدّدة ) بما يؤدي إلى المساهمة الفعالة في تعزيز النمو الاقتصادي والتتافسية الوطنية والعدالة الاجتماعية. بضض الأهداف الرئيسبة: • تحقيق أمن الطاقة. • تعظيم الموارد المحلية (تقليدية ومتجددة)، من خلال زيادة مجمل انتاج الطاقة من الموارد المحلية وتعظيم درجة الإعتماد عليها. زيادة المساهمة الفعلية الإقتصادية للقطاع فى الإعماد الدخل القومي. 
المحود الثالث :المعرفة والابتكار والبحث العلمي: بحلول عام 2030 تصبح مر مجتمع مبدع ومبتكر ومنتج للعلوم والتكنولوجيا والمعارف، يتميز بوجود نظام متكامل يضمن القيمة التتموية للابتكار والمعرفة، ويربط تطبيقات المعرفة ومخرجات الابتكار بالأهداف والتحديات الوطنية. بعض الأهداف الرئيسية: تهيئة بيئة محفزة لإستيعاب وتوطين وإنتاج المعرفة • تفعيل وتطوير نظام وطني متكامل للإبتكار قادر على تحويل المعرفة إلى قيمة تنموية

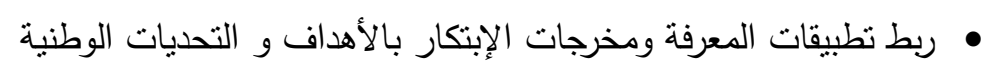
المحور الرلبع: الشفافية وكفاءة المؤسسات الحكومية : بحلول عام 2030 يصبح الجهاز الإداري جهازاً كفء وفعال، يحسن إدارة موارد الدولة وينسم بالثفافية والنزاهة ويخضع للمساءلة

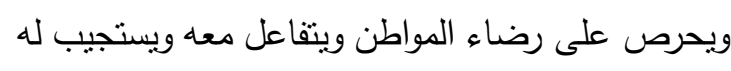

يعض الأهداف الرئيسبة: • جهاز إدارى يتميز بالكفاءة والفاعلية والمواءمة مع المتغيرات. • • تقديم خدمات متميزة مرتفعة الجودة تستخدم الأساليب الحديثة. • نظام يتسم بالثفافية يستجيب ويتفاعل مع المواطن ويخضع للمسائلة المجتمعية.

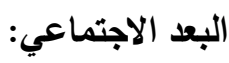
المحور الخامس العدالة الاجتماعية: بحلول عام 2030 من المستهدف بناء مجتمع عادل متكاتف يتميز بالمساواة في الحقوق والفرص الاقتصادية والاجتماعية والسياسية وبأعلى درجة

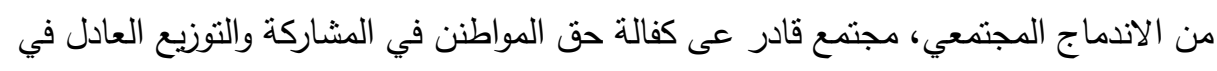

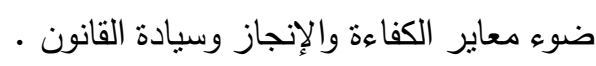
بعض الأهداف الرئيسبة:

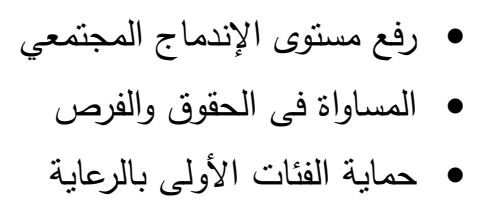


المحور السادس الصحة: بحلول عام 2030 يتمتع كافة المصرين بالحق في حياة صحية

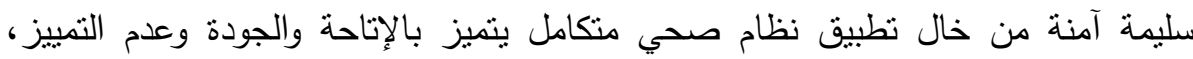
وقادرعلى تحسن المؤشرات الصحية عن طريق تحقيق التغطية الصحية والوقائية والتدخل المبكر والئه لكافة المواطنن بما يكفل الحماية المالية لغير القادرين. بصض الأهداف الرئيسية:

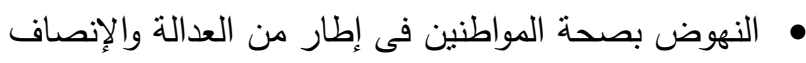
• تحقيق التغطية الصحية الثاملة لجميع المصريين مع ضمان جودة الخدمات المقدمة • حوكمة قطاع الصحة،وتحسين إدارة موارد القطاع فى إطار من الثفافية والمساءلة

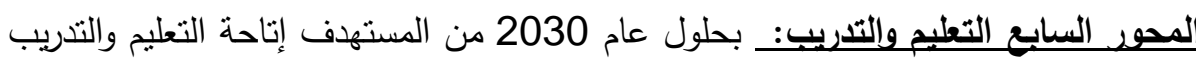
للجميع بجودة عالية دون تمبيز ، وفي إطار نظام مؤسي، كفء وعادل، ومستدام، ومرن. بعض الأهداف الرئيسية: • اتفاق جودة النظام التعليمي مع النظم العالمية • بكون التعليم متاحا للجميع دون تمبيز

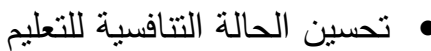

المحور الثامن الثقافة: بحلول عام 2030 من المستهدف بناء منظومة قيم ثقافية إيجابية في

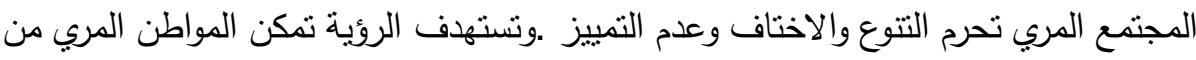
الوصول إلى وسائل اكتساب المعرفة وفتح الآفاق. بعض الأهداف الرئيسبة: • تكون الصناعات الثقافية مصدر قوة • • رفع كفاءة وفاعلية المؤسسات الثقافية • ماية وصيانة التراث 
البعد البيئي: المحور التاسع البيئة: بحلول عام 2030 يكون البُعد البيئي محوراً أساسياً في كافة القطاعات التتموية والاقتصادية بشكل يحقق أمن الموارد الطبيعية ويدعم عدالة استخدامها والاستغلال الأمنل لها والاستثمار فيها وبما يضمن حقوق الأجيال القادمة فيها.

بعض الأهداف الرئيسية: • الإدارة الرشيدة والمستدامة لأصول الموارد الطبيعية

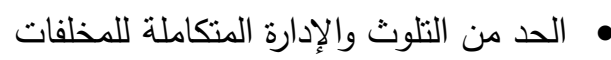

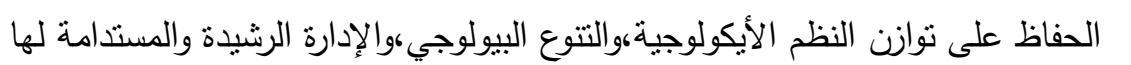

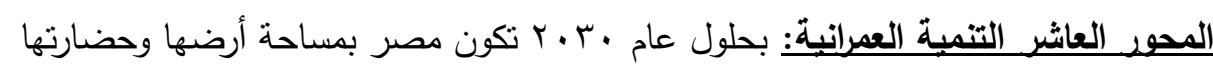
وخصوصية موقعها قادرة على استيعاب سكانها ومواردها في ظل إدارة تتمية مكانية أكثر توازناً وترتقي بجودة حياتهم.

بعض الأهداف الرئيسبة:

• زيادة مسطح المعمور بما يتتاسب مع الموارد وزيادة حجم السكان فى الحاضر والمستقبل

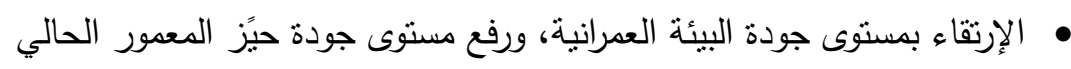
• • تعظيم إستغلال الموقع الإستراتيجي لمصر إقليمياً ودولياء

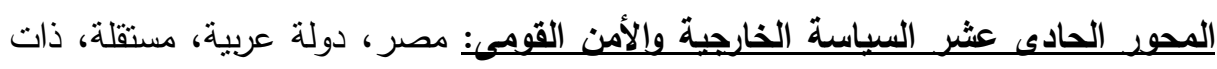
سيادة، تتبنى سياسة خارجية نشطة وفعالة ومتوازنة للحفاظ على أمنها القومي المحور الثانى عشر السياسة الداخلية : نظام سياسي ديموقراطي يحترم مبادئ حقوق الإنسان ويقوم على سيادة القانون • ع - السياسة المالية نشأتها وتطورها وأدواتها: يقصد بها منذ أن استعملها الإغريق تدبير أمور الدولة، (السيد عطية، ب99 (1) كما استخدمت بمعنى علم إدارة الدول، ومنها أنها

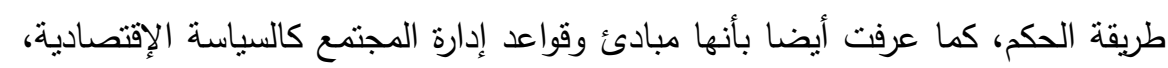
السياسة التجارية، السياسة المالية، السياسة النقدية. 
إن السياسة الاقتصادية تشمل مجموعة من السياسات، كالسياسة المالية والسياسة النقدية

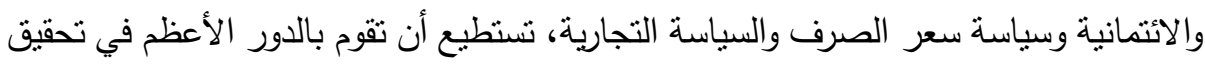

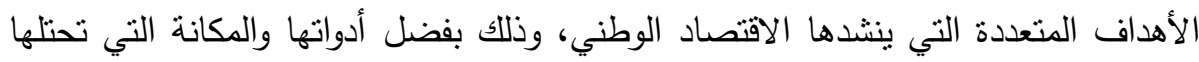

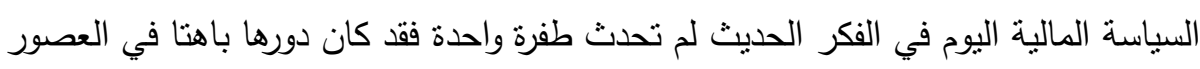

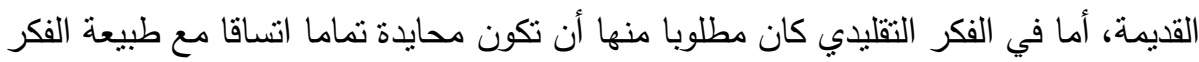
السائد أنذاك وبقي حال السياسة المالية على هذا الوضع إلى أن ظهر في الأفق الأزمات

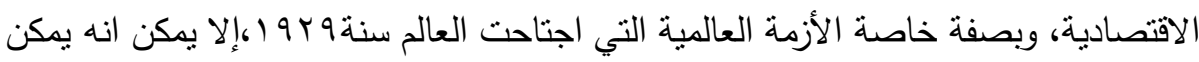

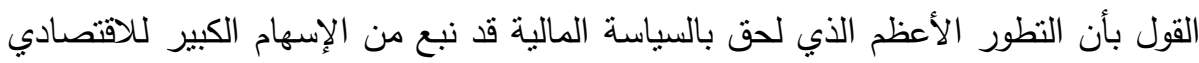

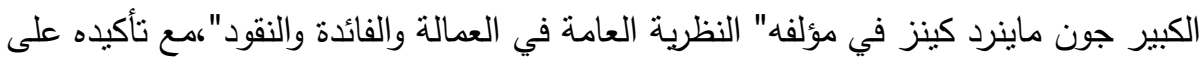

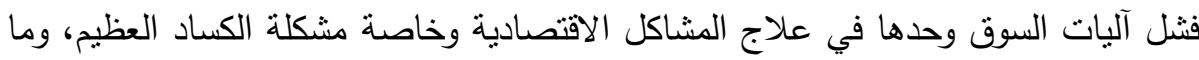
ترتب عليه في الواقع العملي من ضرورة تنبي أراء كينز الخاصة بتدخل الدولة في النشاط

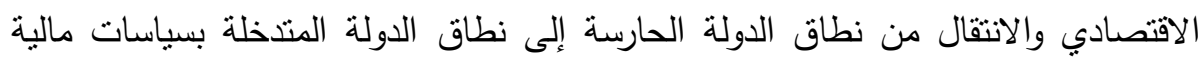

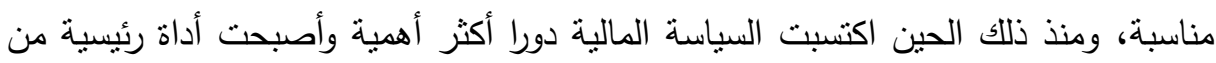

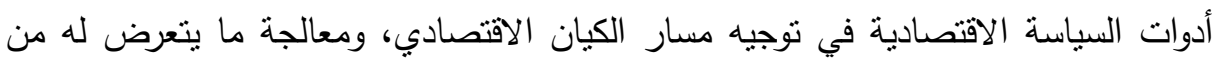

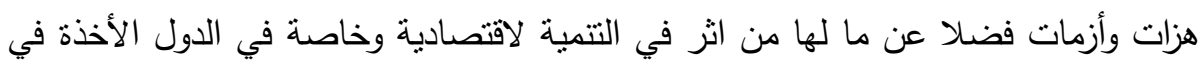

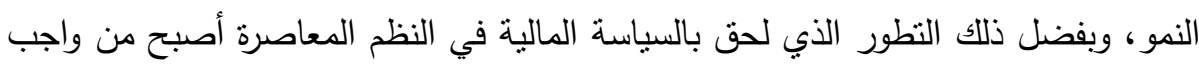
الدولة ولزاما عليها أن تتخخل في توجيه الاقتصاد الوطني.

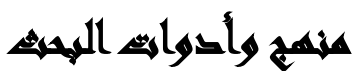

• استخدام المنهج الاستقرائي عن طريق استقراء الدراسات والأبحاث والكتب والدوريات العربية والأجنبية التي تمت في مجال السياسة المالية والتعليم العالى والتتمية المستدامة وذللك لخدمة أهداف البحث بهدف توضيح المفاهيم والعلاقات بينها. • استخدام المنهج التحليلي الوصفي وذلك بهدف تحليل البيانات التي تتوافر حول مشكلة الدراسة و الوقوف على العلاقة بين مختلف متغيرات الدراسة. 


\section{كما تمثلت الأدوات البحثية في:}

1- الإحصائيات المتعلقة بالأوضاع الحالية لمنظومة التعليم العالى في مصر خلاد فترة

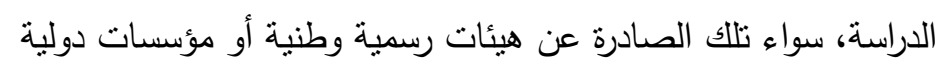

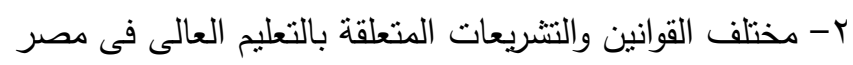

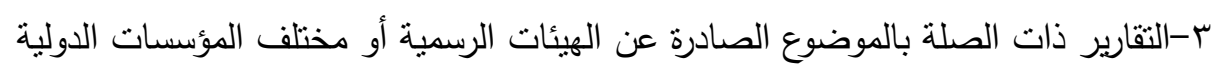
ع - تم عمل مقابلات شخصية متعمقة مع مسئولى التعليم الجامعي الخاص فى وزارة التعليم العالي مبنية على أسئلة إستبيان مشتقة من وثثقة "إستراتيجية التتمية المستدامة:روئية

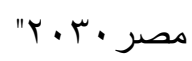

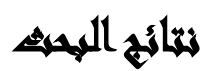

ولإجابة على التساؤل الفرعي الأول وهو: هل تستطيع الجامعات الخاصة والأهلية

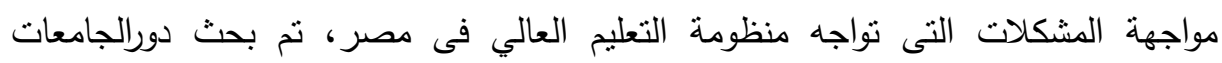
الخاصة والأهلية في معالجة كل مشكلة من مشكلات منظومة التعليم العالي التى طرحها

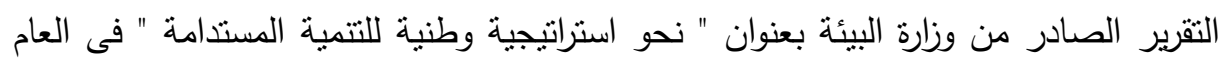

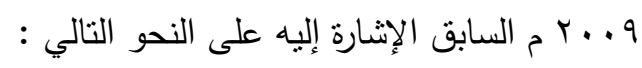

1 - هل تسنطيع الجامعات الخاصة تخفيف الضغط على التعليم العالى بسبب زيادة السكان

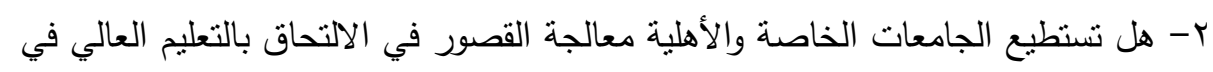
بعض المناطق منل جنوب سيناء والصعيد والوادي الجديد ومطروح r- هل نسنطيع الجامعات الخاصة والأهلية معالجة القصور فى نوعية ولنية التعليم

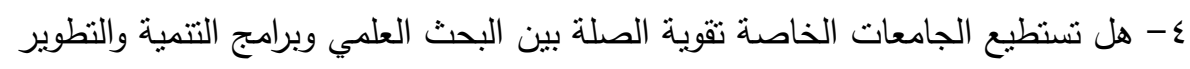
ه- هل تستطيع الجامعات الخاصة والأهلية توفيرميزانية الدولة المخصصة للبه البحث العلمي 


\section{وسنتناول فيما يلى الإجابة على التساعل الأول:}

\section{1-هل تستطيع الجامعات الخاصة والأهلية تخفيف الضغط على الإلتحاق بالتعليم العالى الإله}

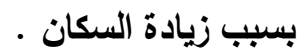

فيما يلى تطور أعداد الطلاب المقيدين بالجامعات الخاصة والأهلية منذ إنشائها وحتى بـى باده .4 .17

جدول رقم(ץ): تطور اعداد الطلاب المقيدين فى الجامعات المصرية فى الفترة من عام r.19 1997

\begin{tabular}{|c|c|c|c|c|c|c|c|c|c|c|}
\hline فئسية & تص الثئية & $\frac{200}{\psi}$ & تص الثيشين & لبرية & 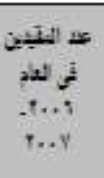 & لتبن & 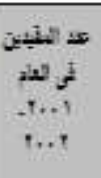 & $\underset{\%}{4}$ & 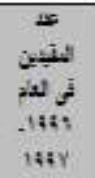 & مزيست التبي الئ \\
\hline$\because \theta, y$ & 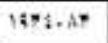 & $\because, y$ & 1.YY.AF & $\mathrm{ry}, \mathrm{A}$ & $1 \leqslant 10 ; 41$ & $2 r, 9$ & 17420 & $r, t$ & $\pi \cdot A, G$ & جانبت المثربية \\
\hline $1 \cdot 1$ & Taו? & $12, \%$ & $\overline{Y Q .1 Y}$ & 10,8 & p.m & 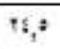 & WiYs & $4, y$ & riar! & 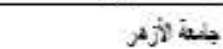 \\
\hline$r$ & 8209 & $\because$ & $0.1 \mathrm{~A}$ & $\because$ & $7: 2 \mathrm{y}$ & $\because$ & T+4. & 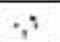 & 198. & أخذيبك \\
\hline$P, A$ & וחוחו & $y$ & 14.25 & $\because 2$ & $1 . \mathrm{rV}$ & $\because$ & זו & , & $7 \$ 3$ & 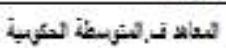 \\
\hline$\because$ & s? & , & ors: & 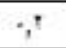 & $5 .+7$ & $\because$ & $\because$ & $1, T$ & ery. & لجنية الهريكية \\
\hline 8,2 & $1+x=4$ & 47 & vars? & $1, A$ & sir. & $?$ & AtA. & $\gamma^{2}$ & 170 & لجابث الذصة \\
\hline $17 ;$ & \&.YYAT & 17 & FA? & 10,7 & 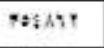 & $1 \%, 1$ & Y.Yen & $4 ;$ & rar.y & سند أمبا لفيدة \\
\hline$\because$ & niry & $\because 5$ & viv & $\because 4$ & r.m & $1, Y$ & A211 & $\because$ & Y4:4 & 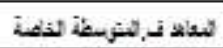 \\
\hline 1,2 & $4: 2 \times 11$ & $y$ & ravas & $r$ & 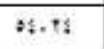 & $7, ;$ & $18+4$ & $r, 4$ & $y+\gamma$ & 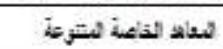 \\
\hline $1 .$. & res?:at & f.. & 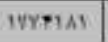 & $1 .$. & reat.t & $1 .$. & $2 . .14 \%$ & 1.. & T.5ian & لإجلكو \\
\hline
\end{tabular}

المصدر: إعداد الباحث من خلال الموقع الإلكترونى لوزارة التعليم العالى واحصائيات الجهاز المركزى للتعبئة العامة

\section{من الجدول السابق يمكن استخلاص الآتى:}

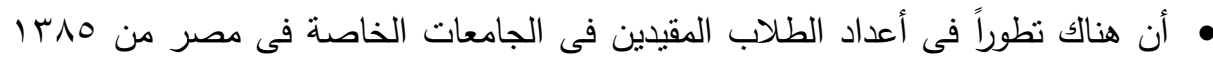

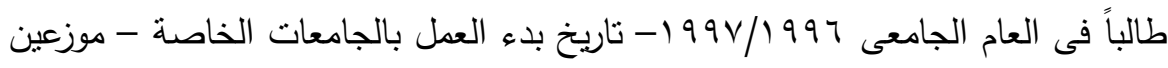

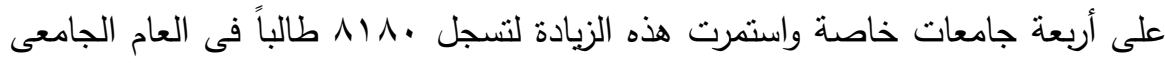

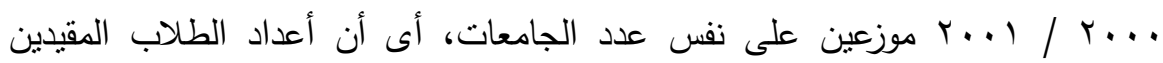


بالجامعات الخاصة قد تضاعف أكثر من خمس مرات فى فترة ثلاث سنوات فقط ،فى حين ظل عدد الجامعات الخاصة العاملة كما هو أربع جامعات.

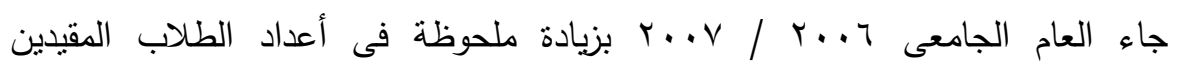

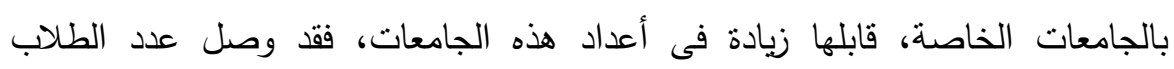

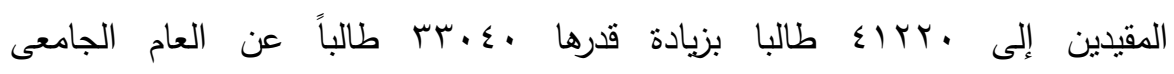

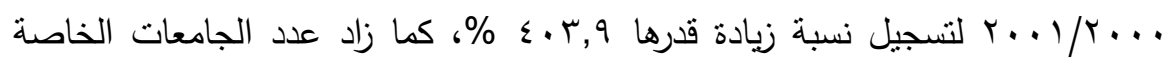

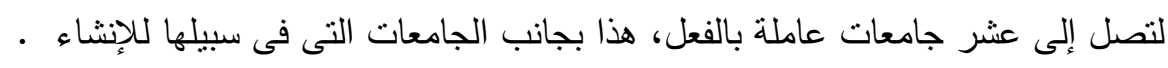

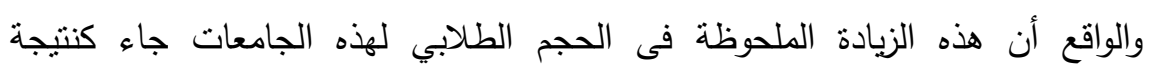

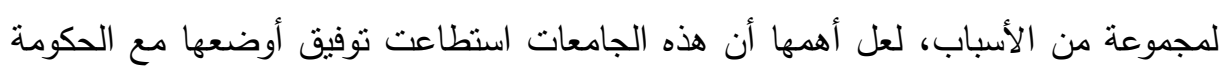
المصرية، حيث نم الاعتراف بالثهادات التى تمنحها هذه الجامعات بعد معادلتها بالثهادات التهات التهات

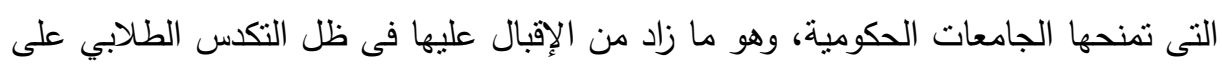

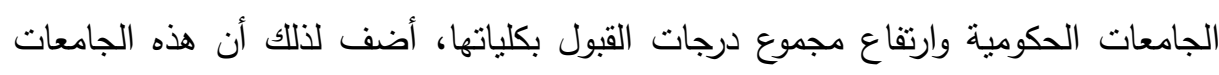

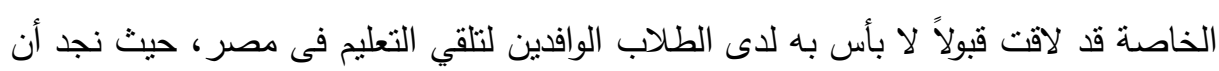

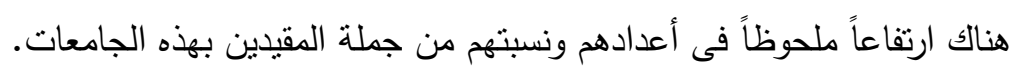

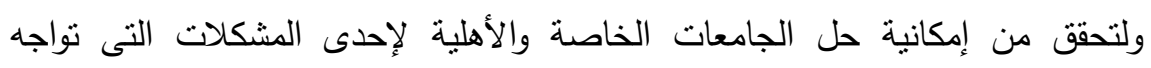
منظومة التعليم العالي فى مصر ، وهى التكدس الطلابى فى الجامعات الحكومية، كان لابد البدات

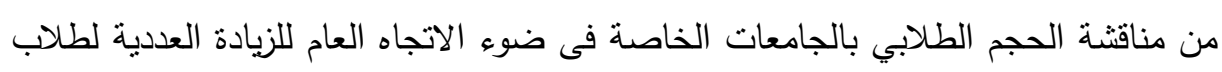
التعليم الجامعى فى مصر ، حيث يتضح من الجدول أن هناك زيادة فى نسبة الطلاب المقبدين

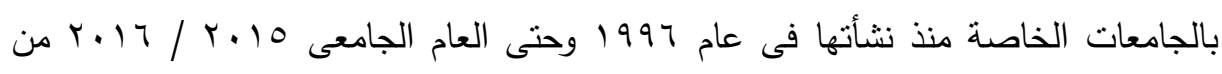

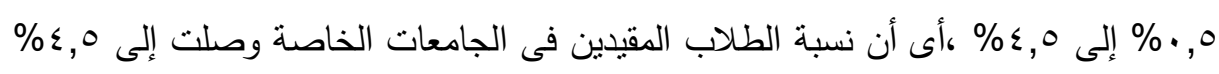
من جملة الطلاب المقيدين بالتعليم الجامعى فى مصر طوال فترة زمنية بلغت عثرين عالمال

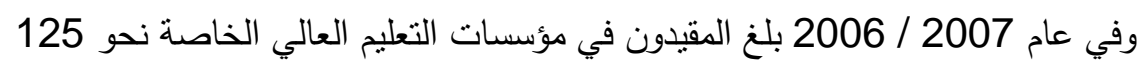
ألف طالب وطالبة بنسبة 20 ٪ من مجموع الطلاب المسجلين في نظام التعليم العالي كله، منهم نحو 6 \% 48,000 ( طالب وطالبة ) في الجامعات الخاصة والباقي في المعاهد العليا 


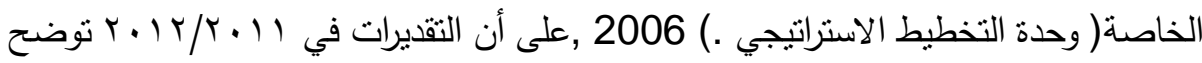
أن الجامعات الخاصة باستثاء الجامعة الأمريكية بالقاهرة - مقيد بها نحو وعلى الرغم من ضآلة هذه النسبة إلا أنه بالنظر للعدد المطلق نجد أن أعداد الطلاب

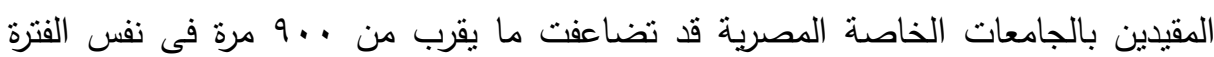

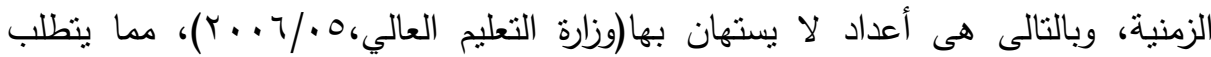
الاهتمام بهذه النوعية من الجامعات، وبالرغم من هذه الزيادة العددية لطلاب الجامعات

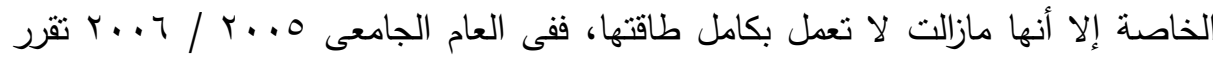
قبول (10) ألف طالب بالجامعات الخاصة، إلا أن العدد الذى ثم قبوله فعلياً لم يتعد . .. طالب أى حوالى (rT\%) فقط من العدد المقرر قبوله، وهي نسبة ما زالت غير كافية لتخفيف العبء الطلابي عن الجامعات الحكومية كمبرر وراء إنثاء هذه الجامعات . وقد

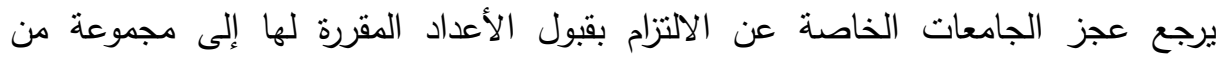
الأسباب لعل أهمها ضوابط القبول خاصة فى الكليات العملية التى اثنترطت حد أدنى الهیى

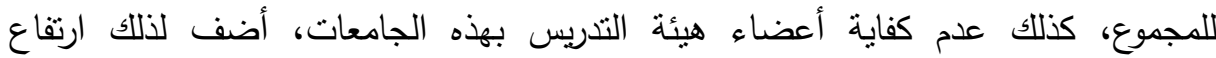

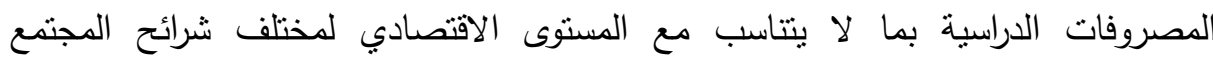
المصري،حيث نراوحت المصروفات الدراسية فى كليات الجامعات الخاصة المصرية للعام

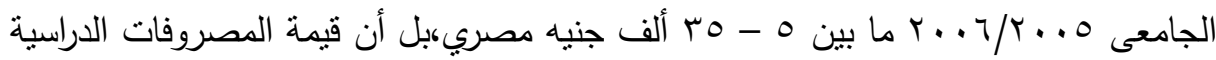
فى بعض هذه الجامعات يتم دفعها بالعملات الأجنبية (إسترليني) كما فى جامعتى الأهرام

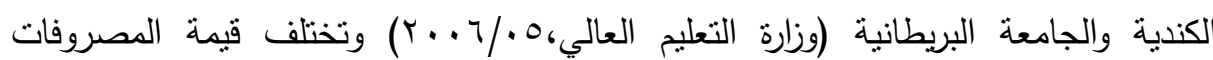
الدراسية حسب التخصص،حيث نجد ارتفاعها فى التخصصات العطلية مثل الطب والهندسة والصيدلة، فى حين تتخفض قليلا فى التخصصات النظرية منل اللغات والترجمة والتربية

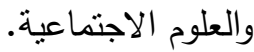

وللإجابة على التساؤل الثاني من التساؤلات البحثية:هل تسنطيع الجامعات الخاصة

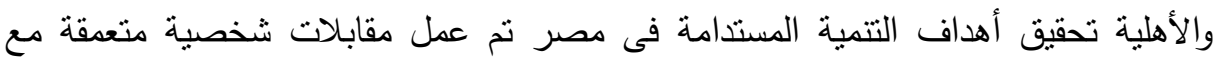
مسئولى التعليم الجامعي الخاص فى وزارة التعليم العالي مبنية على أسئلة إستبيان مشتقة من 
وثيقة "إستراتيجية النتمية المستدامة :رؤية مصر • ب • ب"والتى تتكون من ثلاث أبعاد (إقتصادى - إجتماعي - بيئي) السابق الحديث عنها كالتالي: البعد الاقتصادي المحور الأول التنمية الاقتصادية: بحلول عام 2030 يكون الاقتصاد المصري اقتصاد سوق

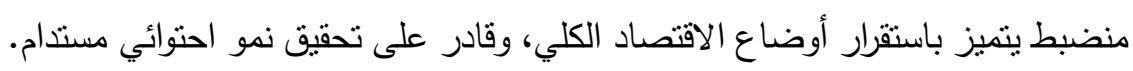
بعض الأهداف الرئيسية: • • تحقيق نمو إحتوائي مستدام ومتوازن

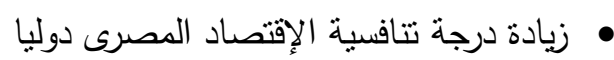

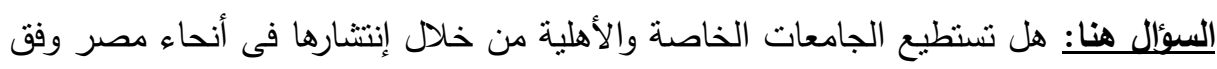
تخطيط دقيق لإحتباجات كل إقليم ومحافظة تحقيق الأهداف السابقة المحور الثاني الطاقة: بحلول عام 2030 يصبح قطاع الطاقة قادراً عى تلبية كافة منطلبات التتمية الوطنية المستدامة من موارد الطاقة وتعظيم الاستفادة الكفؤة من مصادرها المتتوعة (تقليدية ومتجدّدة). بعض الأهداف الرئيسبة: • ت تحقيق أمن الطاقة

• تعظيم الموارد المحلية (تقليدية ومتجددة)، من خلال زيادة مجمل انتاج الطاقة من الموارد المحلية وتعظيم درجة الإعتماد عليها

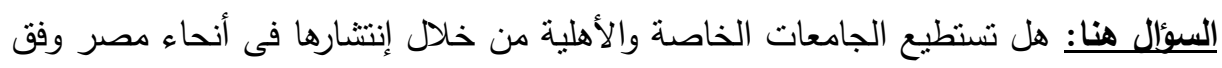
تخطيط دقيق لإحتياجات كل إقليم ومحافظة تحقيق الأهداف السابقة

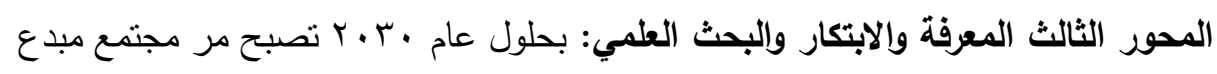
ومبتكر ومنتج للعلوم والتكنولوجيا والمعارف، يتميز بوجود نظام متكامل.

بعض الأهداف الرئيسبة: تهيئة بيئة محفزة لإسنتعاب ونوطين وإنتاج المعرفة • تقعيل وتطوير نظام وطني متكامل للإبتكار قادر على تحويل المعرفة إلى قيمة تتموية 
السؤال هنا: هل تسنطيع الجامعات الخاصة والأهلية من خلال إنتشارها فى أنحاء مصر وفق

تخطيط دقيق لإحتياجات كل إقليم ومحافظة تحقيق الأهداف السابقة . المحور الرابع الثفافية وكفاءة المؤسسات الحكومية: بحلول عام 2030 يصبح الجهاز

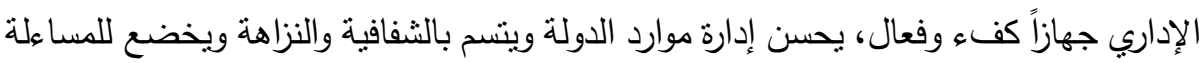
ويحرص على رضاء المواطن ويتفاعل معه ويستجيب له. بعض الأهداف الرئيسية: • • جهاز إدارى يتميز بالكفاءة والفاعلية والمواعمة مع المتغيرات

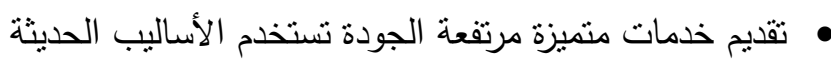

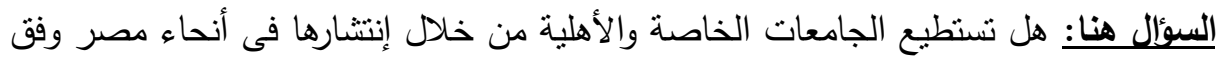
تخطيط دقيق لإحتياجات كل إقليم ومحافظة تحقيق الأهداف السابقة البعد الاجتماعي: - إع المحور الخامس العدالة الاجتماعية: بحلول عام 2030 من المستهدف بناء مجتمع عادل متكاتف يتميز بالمساواة في الحقوق والفرص الاقتصادية والاجتماعية والسياسية وبأعلى درجة

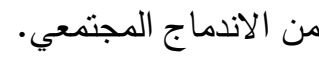
بعض الأهداف الرئيسية:

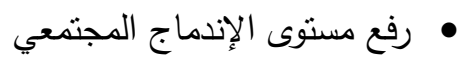

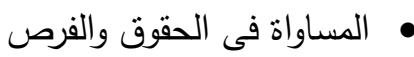

السؤل هنا: هل تستطيع الجامعات الخاصة والأهلية من خلال إنتشارها فى أنحاء مصر وفق وصن تخطبط دقيق لإحتياجات كل إقليم ومحافظة تحقيق الأهداف السابقة.

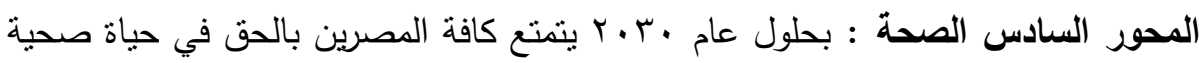
سليمة آمنة من خال تطبيق نظام صحي متكامل يتميز بالإتاحة والجودة وعدم التمييز . بعض الأهداف الرئيسية: • • النهوض بصحة المواطنين فى إطار من العدالة والإنصاف. • تحقيق التغطية الصحية الثاملة لجميع المصريين مع ضمان جودة الخدمات المقدمة. 
السؤال هنا: هل تستطيع الجامعات الخاصة والأهلية من خلال إنتشارها فى أنحاء مصر وفق تخطيط دقيق لإحتياجات كل إقليم ومحافظة تحقيق الأهداف السابقة.

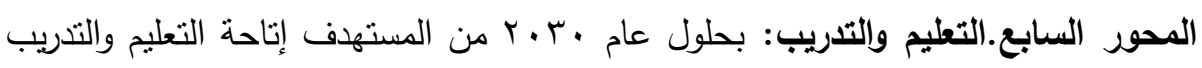

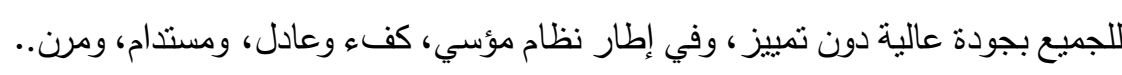

بعض الأهداف الرئيسية: • اتفاق جودة النظام التعليمي مع النظم العالمية • بكون التعليم متاحا للجميع دون تمييز

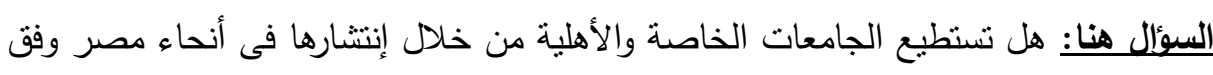
تخطيط دقيق لإحتياجات كل إقليم ومحافظة تحقيق الأهداف السابقة. المحور الثامن الثقافة: بحلول عام 2030 من المستهدف بناء منظومة قيم ثقافية الإهية إيجابية في المجتمع المري تحرم التتوع والاختاف وعدم التمييز . بعض الأهداف الرئيسبة:

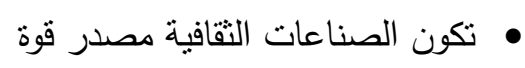
• • • رفع كفاءة وفاعلية المؤسسات النقافية

السؤال هنا: هل نستطيع الجامعات الخاصة والأهلية من خلال إنتشارها فى أنحاء مصر وفق وفئق تخطبط دقيق لإحتياجات كل إقليم ومحافظة تحقيق الأهداف السابقة. البعد البيئي: - n البئ المحور التاسع البيئة: بحلول عام 2030 يكون البُعد البيئي محوراً أساسياً في كافة القطاعات التتموية والاقتصادية بشكل يحقق أمن الموارد الطبيعية. بعض الأهداف الرئيسبة:

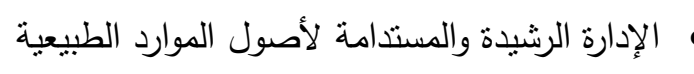

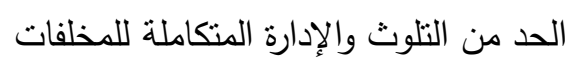

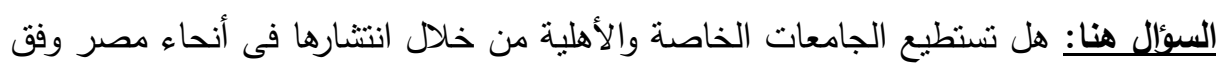
تخطيط دقيق لإحتياجات كل إقليم ومحافظة تحقيق الأهداف السابقة .

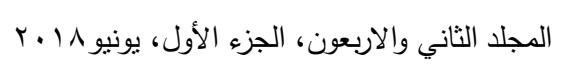


المحور العاشر التنمية العمرانية: بحلول عام 2030 نكون مصر بمساحة أرضها وحضارتها وخصوصية موقعها قادرة على استيعاب سكانها ومواردها في ظل إدارة تتمية مكانية أكثر نوازنا وترتقي بجودة حياتهم. بعض الأهداف الرئيسية: • يادة مسطح المعمور بما يتتاسب مع الموارد وزيادة حجم السكان فى الحاضر والمستقبل

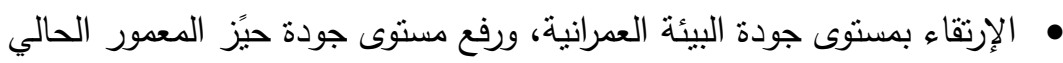

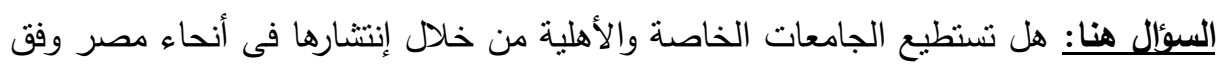
تخطيط دقيق لإحتياجات كل إقليم ومحافظة تحقيق الأهداف السابقة المحور الحادى عثر السياسة الخارجية والأمن القومى: مصر، ، دولة الاهدية عربية، مستقلة، ذات

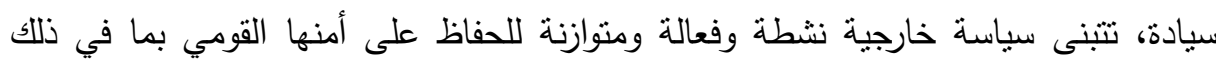

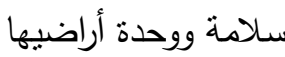

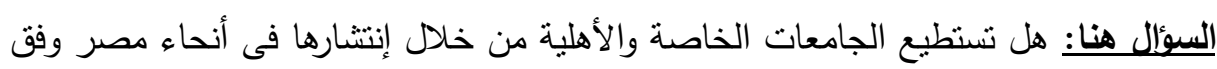
تخطبط دقيق لإحتياجات كل إقليم ومحافظة تحقيق الأهداف السابقة المحور الثانى عشر السياسة الداخلية: نظام سياسي ديموقراطي يحترم مبادئ حقوق الإنسان ويقوم على سيادة القانون.

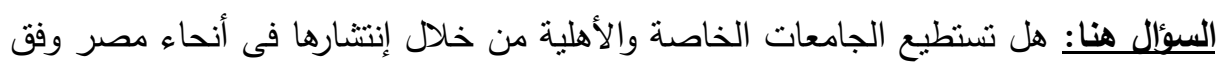
تخطبط دقيق لإحتياجات كل إقليم ومحافظة تحقيق الأهداف السابقة. وللإجابة على التساؤل الفرعي الثالث ما السياسات المالية الداعمة للجامعات الخاصة الثانة والأهلية فى مصر، تم استعراض التجارب الدولية والإقليمية فى توظيف السياسة المالية لدعم

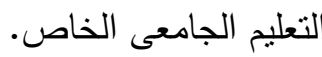




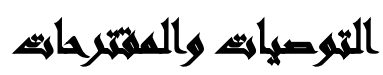

استخدام أسلوب التخطبط الإستراتيجي فى تخطيط السياسة المالية الداعمة للجامعات

الخاصة والاهلية لمواجهة تحديات منظومة التعليم العالى والتتمية المستدامة فى مصر .

يرى الباحث أنه يمكن للجامعات الخاصة والأهلية بشئ من التخطيط للسياسات المالية ولئه

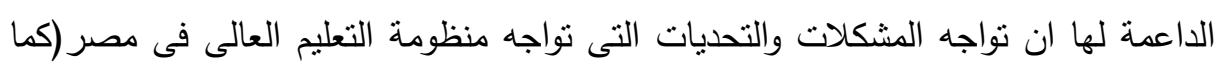
جاءت فى تقرير" نحو استراتيجية وطنية للتتمية المستدامة "، كذلك تحقيق اهداف التتمية

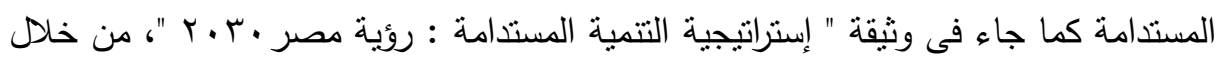
التخطيط الإستراتيجى للسياسة المالية الداعمة للجامعات الخاصة والأهلية ،حيث تعددات

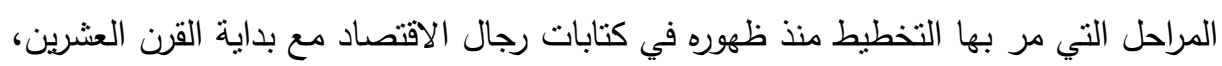

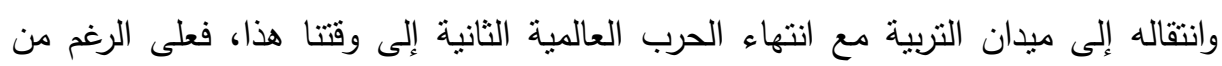

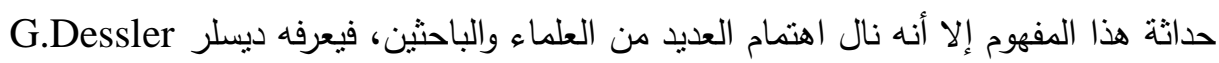
بأنه عملية صياغة وتحديد رسالة المؤسسة من خلال التوفيق بين إمكاناتها ومنطلبات البيئة المحيطة بها (Dessler,G. 2004)، ويعرفه فيدلر B.Fidler بأنه مجموعة من الأفعال المنظمة لتحقيق مجموعة من الأهداف المنشودة في فترة زمنية محددة، وذلك من خلال

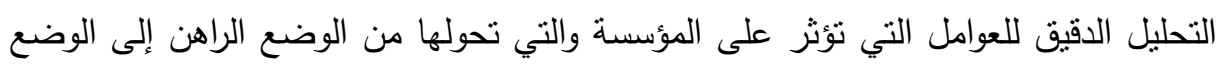

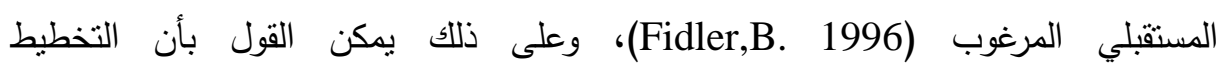

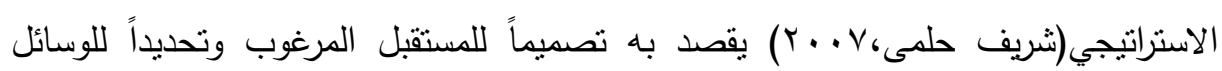
الكفيلة بإحداثه وهو عبارة عن عملية تبدأ بوضع الأهداف في ضوء جوانب القوة والضعف في لئل المؤسسة والفرص والمخاطر التي تواجهها في بيئتها الخارجية ثم تحديد الاستراتيجيات لئه والسياسات والخطط التفصيلية الكفيلة بتحقيق تلك الأهداف، ويرتبط مفهوم التخطبط

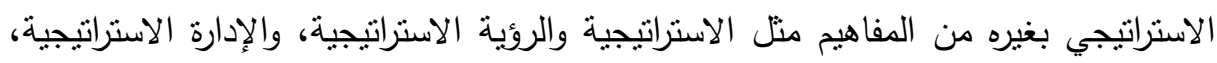

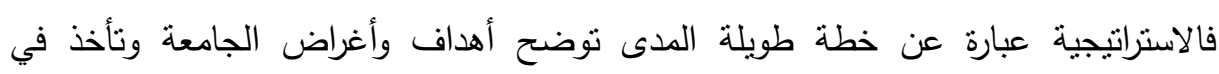

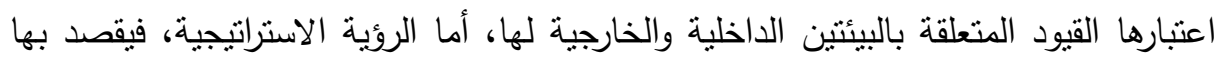
تصور للمستقبل المرغوب للمؤسسة، قائم على دراسة ماضيها وأوضاعها الداخلية وما يندرج

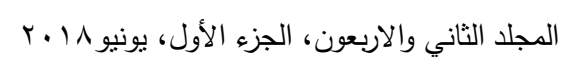


تحتها من مواطن القوة والضعف وما تتعرض له من مثيرات خارجية قد تمثل فرصاً يمكن الاستفادة منها أو مخاطر مستقبلية. (فاتن عزازى، ع ـ . ب).

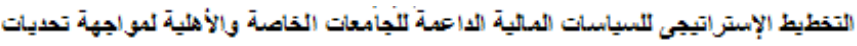

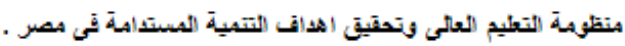

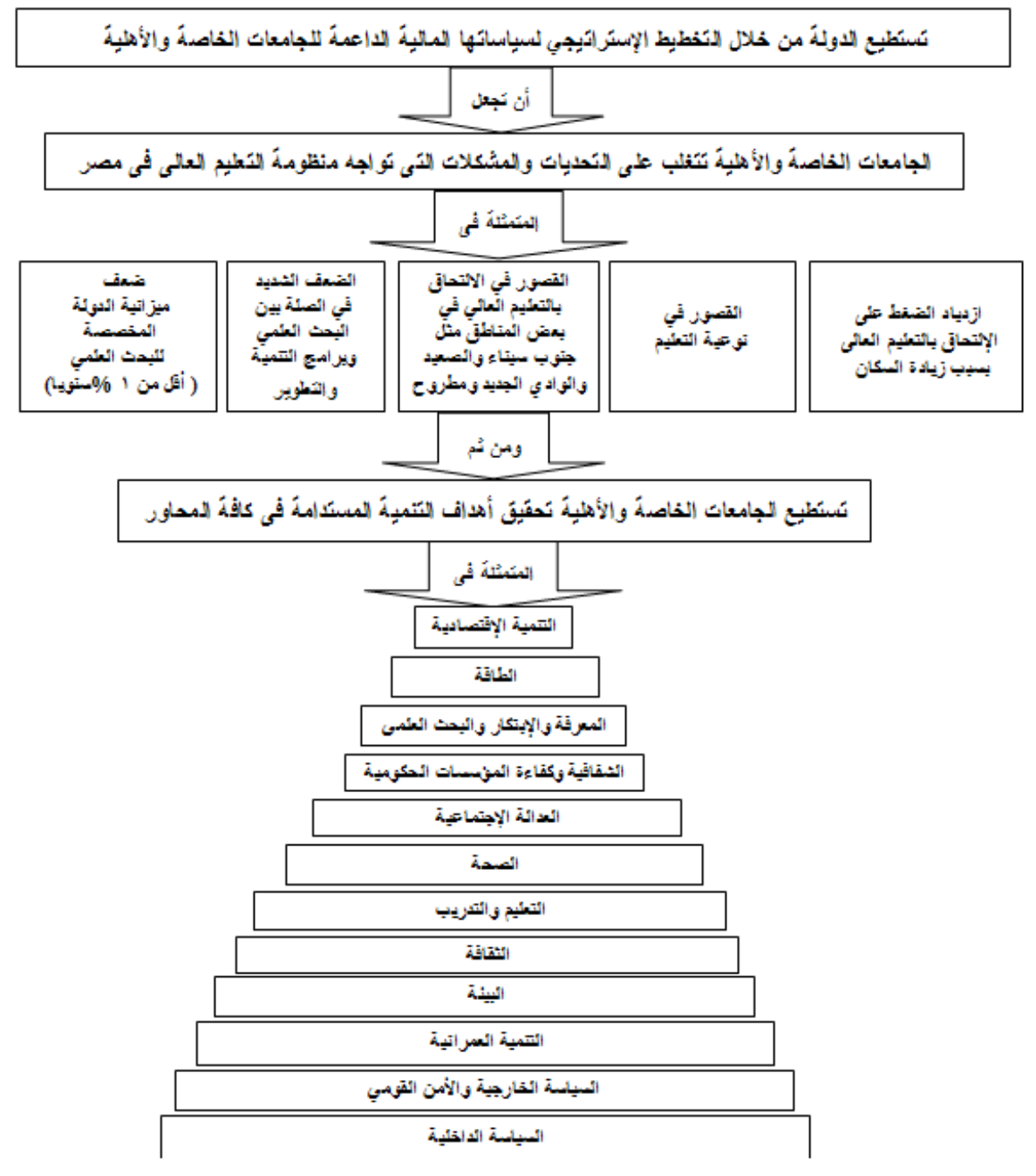

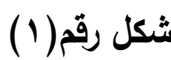
المصدر: إعداد الباحث 


\section{المران}

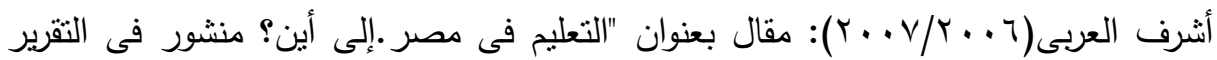

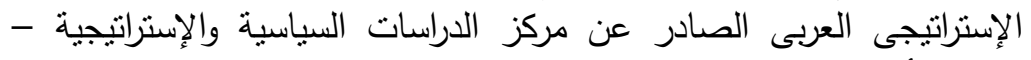

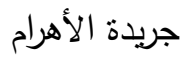

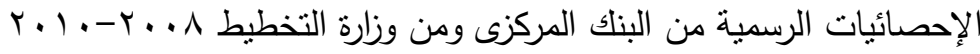

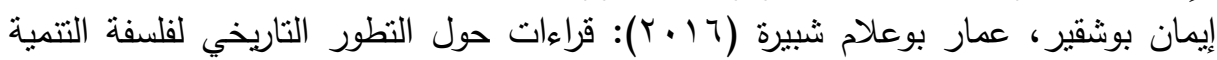

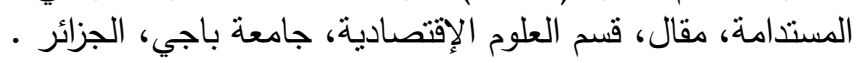

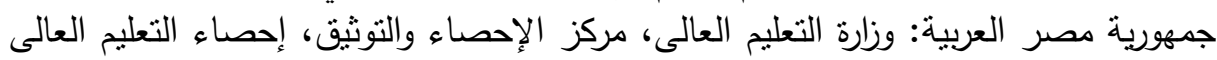

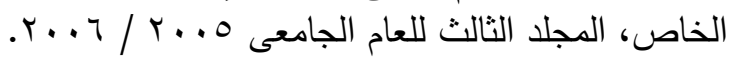

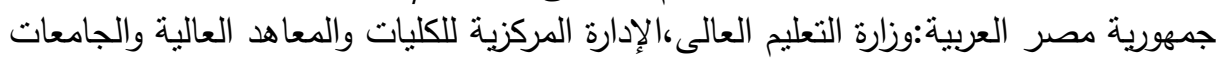

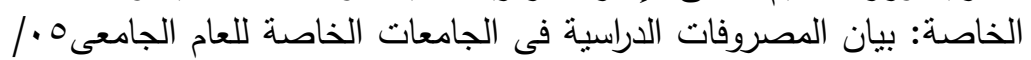

$$
\text { r... T }
$$

سمير رياض هلال وآخرون(·( •ب): دراسة تمويل التعليم العالي،المرحلة الأولى، إعداد

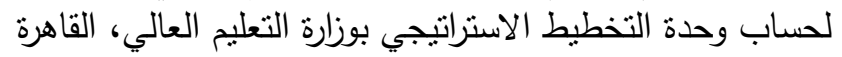

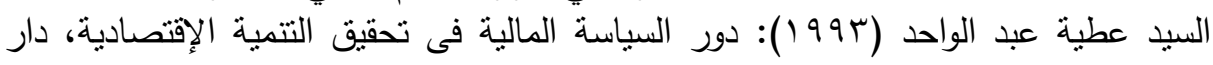

$$
\text { النهضة العربية، القاهزة. }
$$

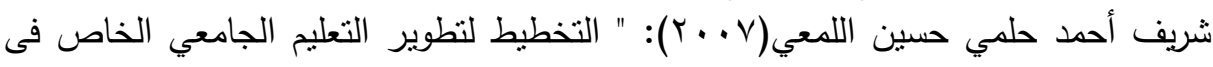

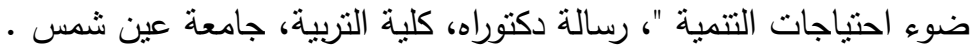

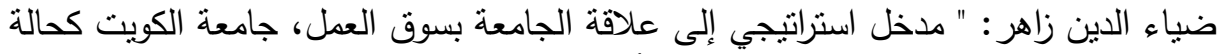

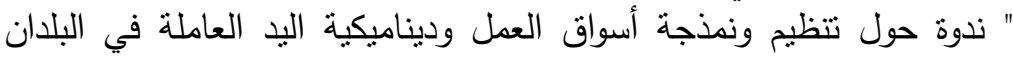

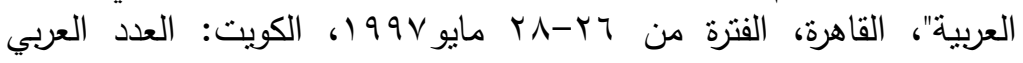

$$
\text { اللتخطيط }
$$

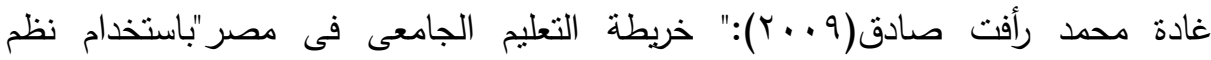
المعلومات الجغرافية دراسة فى جغرافية الخدمات،رسالة دكتوراه، كلية الأداب،

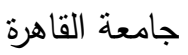

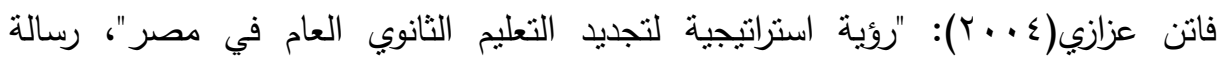

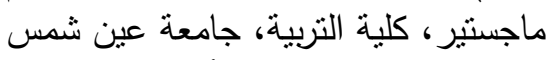

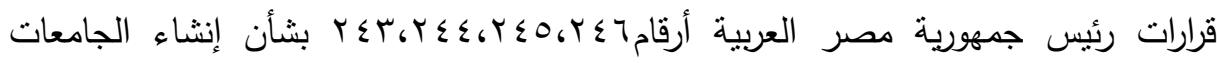

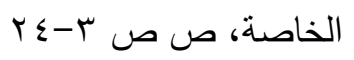

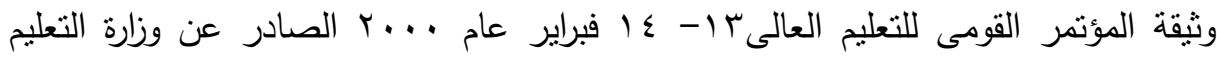
العالى والدولة للبحث العلى العى العى العيل

وزارة التعليم العالى : دليل التعليم العالى فى مصر ، القاهرة، ج. ب. T

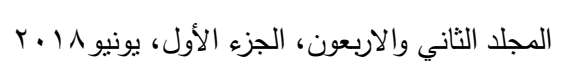


وزارة الدولة لشئون البيئة: اللجنة الوطنية للتتمية المستدامة، نحو استراتيجية وطنية للتتمية

المستدامة،"وثثقة إطار الإستراتيجية الوطنية للتنمية المستدامة ومنهجية إعداد المنية

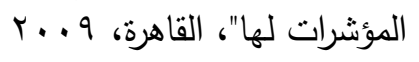

وزارة الدولة لشئون البيئة: اللجنة الوطنية للتمية المستدامة،لا نحو إستراتيجية وطنية للتتمية

المستدامة، "وتثقة إطار الإستراتيجية الوطنية للتتمية المستدامة ومنهجية إعداد

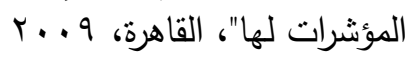

Hppt://unsdsn.org/what-we-do/sustainable-developmentgoals/processes

Dessler, G.( 2004): " Management Principles and Practices for tomorrow's Leaders", Person Education Inc., New Jersey.

Fidler, B.( 1996):"Strategic Planning for School Improvement", Pitman Publishing, London.

Hill, C.W\& Jones, G.R.( 2001) :" Strategic Management, An International Approach", 5th ed. Houghton Mifflin Company, New York.

Road Map towards the Implementation of the United Nations Millennium Declaration, Report of the SecretaryGeneral,General Assembly,Millennium Summit,United Nations, 6 September 2001, New York. 
فرج عزت وآخرون

\title{
STRATEGIC PLANNING OF FINANCIAL POLICIES \\ IN SUPPORT OF PRIVATE UNIVERSITIES TO \\ DEVELOP THE HIGHER EDUCATION SYSTEM AND \\ ACHIEVE THE OBJECTIVES OF SUSTAINABLE DEVELOPMENT IN EGYPT.
}

Ezat, F. ${ }^{(1)}$; Al Saman, A. ${ }^{(2)}$; El Sayed, Lamia,. ${ }^{(3)}$ and kamel, B..$^{(4)}$ 1) Faculty of Commerce, Ain Shams University 2) Faculty of, Economic \& political Sce, Cairo University 3) Faculty of Education, Ain Shams University 4) Faculty of Economic \& Management, 6 oct University

\begin{abstract}
The purpose of the research is to explain the role of private universities (established by Law No. 101 of 1992, as amended by Law No. 12 of 2009 in the matter of private universities) in solving the problems facing the higher education system and thus achieving the objectives of sustainable development in Egypt through strategic planning of financial policies supporting private universities in Egypt.

The research sought to answer the main question: To what extent can the financial policies supporting private universities develop the higher education system and thus achieve the goals of sustainable development in Egypt?

The researcher used a number of methodologies such as the descriptive approach, The case study method was used to describe the reality of the higher education system and sustainable development in Egypt and the analytical methodology of historical data to deal with the development of private universities in Egypt as well as the development of the concept of sustainable development globally and locally, as well as the role of private universities in solving the problems of the higher
\end{abstract}

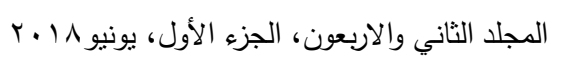




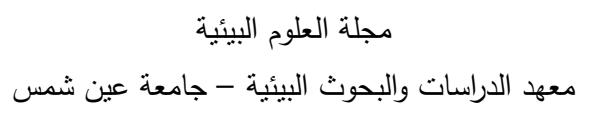

education system and achieving the goals of sustainable development in Egypt.

A number of interviews were conducted based on questions derived from the axes of sustainable development: Egypt's Vision 2030 with the university education officials of the Ministry of Higher Education. The researcher reached a number of results, the most important of which is that private universities can overcome all problems of university education in Egypt, In order to do so as a result of several reasons, most notably the lack of vision and financial policies planned by the State to support the establishment of such universities and therefore the establishment of these universities comes randomly and according to the wishes of the service provider without the State has no role but to approve the request for construction provided by the parties wishing to Willing private universities, and the current study recommended that there should be a strategic planning and financial policies in support of private universities to be established. 